\title{
Heliotropium L. (Boraginaceae - Heliotropioideae) de Pernambuco, Nordeste do Brasil 1,4
}

José Iranildo Miranda de Melo ${ }^{2,3}$

Margareth Ferreira de Sales ${ }^{2}$

\begin{abstract}
RESUMO
Foi realizado o estudo taxonômico do gênero Heliotropium L. no estado de Pernambuco, utilizando-se espécimes coletados em campo por um período de 16 meses, além de materiais de empréstimo e/ou doação provenientes de vários herbários nacionais. Verificou-se a ocorrência de sete taxa: $H$. angiospermum Murray, $H$. curassavicum L., H. elongatum (Lehm.) I.M. Johnst., $H$. indicum L., $H$. polyphyllum Lehm., H. procumbens Mill e H. ternatum. H. curassavicum e H. ternatum Vahl constituem nova referência para o Nordeste e Pernambuco, Brasil, respectivamente. As espécies mais amplamente distribuídas são $H$. angiospermum, H. elongatum e $H$. procumbens, ocorrendo desde a zona do litoral até a zona das caatingas.
\end{abstract}

Palavras-chave: Heliotropium, Boraginaceae, taxonomia, Nordeste, Brasil

\begin{abstract}
A taxonomic study of the genus Heliotropium L. in the State of Pernambuco was carried out. The survey was based on field studies during 16 months and material provided by loan and donation from different brazilian herbaria. Seven species were recorded: H. angiospermum Murray, H. curassavicum L., H. elongatum (Lehm.) I.M. Johnst., H. indicum L., H. polyphyllum Lehm., $H$. procumbens Mill. and $H$. ternatum Vahl. $H$. curassavicum and $H$. ternatum represent new geographical occurrences from Northeastern and State of Pernambuco, Brazil, respectively. The species most widely distributed were $H$. angiospermum, $H$. elongatum and $H$. procumbens, occurring both since litoral to caatinga's zone.
\end{abstract}

Key-words: Heliotropium, Boraginaceae, taxonomy, Northeastern, Brazil

\section{INTRODUÇÃO}

Heliotropium L. consiste de aproximadamente 300 espécies (Förther, 1998), distribuídas nas regiões tropicais, subtropicais e temperadas (Gangui, 1955); ocorrendo principalmente nas zonas áridas (Gentry, 1993), é considerado um dos maiores e mais complexos da família Boraginaceae (Akhani \& Förther, 1994).
Gürke (1897) posicionou-o em Boraginaceae subfam. Heliotropioideae juntamente com Tournefortia L. Esses gêneros compartilham características como inflorescência escorpióide e estigma cônico, embora Heliotropium possa ser distinguido, facilmente, pelo hábito em geral herbáceo associado ao fruto seco; enquanto em Tournefortia, o hábito é lenhoso e o fruto é carnoso.

\footnotetext{
${ }^{1}$ Parte da dissertação de mestrado do primeiro autor, defendida e aprovada em 22.02.2001, no Programa de PósGraduação em Botânica da Universidade Federal Rural de Pernambuco (PPGB-UFRPE).

${ }^{2}$ Programa de Pós-graduacão em Botânica, Universidade Federal Rural de Pernambuco - 52171-900 - Recife,PE Brasil.

${ }^{3}$ Autor para correspondência: jimmelo@zipmail.com.br

${ }^{4}$ Suporte financeiro: CNPq/PPGB-UFRPE.
} 
As espécies de Heliotropium apresentam pouca importância econômica, sendo alguns de seus representantes utilizados como ornamentais na Europa, destacando-se $H$. europaeum L. (Swingle, 1993). Segundo Fröhlich apud Nash \& Moreno (1981), $H$. indicum L. é uma espécie largamente empregada na medicina popular, em várias regiões do globo.

Para Pernambuco, nenhum trabalho envolvendo a taxonomia de Heliotropium foi desenvolvido, embora listas de espécies possam ser encontradas em Sales et al. (1998), para os brejos de altitude e para um refúgio vegetacional em Buíque (A.P.S. Gomes \& M.J.N. Rodal, dados não publicados).

Haja vista que a família Boraginaceae constitui um táxon euripolínico (Miranda \& Andrade, 1990), foi procedido o estudo da morfologia polínica dos representantes de Heliotropium L. ocorrentes em Pernambuco; auxiliando na delimitação das espécies estudadas (Melo et al., inéd.).

Considerando a escassez de estudos abordando os representantes de Heliotropium, o presente estudo teve por objetivos: a)identificar e descrever as espécies do gênero, ocorrentes em Pernambuco, Brasil, incluindo comentários sobre habitats preferenciais e afinidades; b) atualizar a distribuição geográfica dos taxa, além de c)ampliar os conhecimentos sobre a taxonomia do gênero e contribuir para o projeto Flora de Pernambuco.

\section{Histórico do gênero}

O gênero Heliotropium foi nomeado por Tournefort (1719), sendo efetivamente publicado por Linnaeus (1735). A primeira contribuição para o entendimento da sistemática do gênero foi dada por De Candolle (1845) que, baseado fundamentalmente na forma da antera e no tipo de estigma, propôs quatro seções: Heliotropium sect. Catimas A. DC., Heliotropium sect. Piptoclaina (G. Don) Endl., Heliotropium sect. Heliotropium A.DC. e Heliotropium sect. Orthostachys R.Br. Mais tarde, Bentham \& Höoker (1873/
1876) trataram o gênero Heliophytum A. DC. como sinônimo de Heliotropium, propondo para este último mais uma seção: Heliotropium sect. Heliophytum.

Outro tratamento infragenérico abrangendo todo o gênero Heliotropium foi proposto por Gürke (1897), que aceitou 217 espécies, acomodando-as em sete seções: Heliotropium sect. Messerschmidia DC.; Heliotropium sect. Catimas A. DC.; Heliotropium sect. Monimantha Franch.; Heliotropium sect. Piptoclaina (G. Don) Endl.; Heliotropium sect. Heliotropium A. DC.; Heliotropium sect. Heliophytum (DC.) Benth. \& Höok e Heliotropium sect. Orthostachys R.Br. O tratamento mais recente para as espécies sul-americanas de Heliotropium foi estabelecido por Johnston (1928), reconhecendo 73 espécies e posicionando-as em 10 seções das quais, quatro eram novas ou novas combinações: Heliotrqim Hypsogenia, Heliotrqim Halmyrophila, Heliotropium sect. Plagiomeris e Heliotropium sect. Heliothamnus.

Descrições sucintas de representantes de Heliotropium são encontradas em Floras de vários países como da Argentina (Gangui, 1955), Peru (Macbride, 1960), América Central e Panamá (Gentry \& Janos, 1974), Panamá (Nowicke, 1969), Guatemala (Gibson, 1970), Veracruz (Nash \& Moreno, 1981) e Iran (Akhani \& Forther, 1994).

Förther (1998), estabeleceu um tratamento para a subfamília Heliotropioideae. Neste trabalho, baseado em dados morfológicos e anatômicos, o autor reconheceu 19 seções além de fornecer uma lista de todos os taxa validamente reconhecidos para o gênero Heliotropium.

Apesar de bem representado no Brasil, com estimativa de mais de 25 espécies, os estudos sobre Heliotropium ainda são escassos. Os tratamentos sistemáticos que incluem espécies brasileiras são, na maioria, obras clássicas e antigas, como a monografia de Fresenius (1857/1863), na Flora 
Brasiliensis, onde o autor admitiu um conceito mais restrito para o gênero, considerando para Heliotropium apenas três espécies. As demais, atualmente aceitas como Heliotropium, foram acomodadas nos gêneros Schleidenia, com 28 e Heliophytum, com 12 espécies, respectivamente. Poucas espécies de Heliotropium são referidas em floras regionais como as da Guanabara (Guimarães et al., 1971), do Pico das Almas, Bahia (Harvey, 1995) e para a flora de Santa Catarina (Smith, 1970).

\section{MATERIAL E MÉTODOS}

Área de estudo

O estado de Pernambuco apresenta uma área de $98.087 \mathrm{Km}^{2}$, situando-se na região Nordeste do Brasil entre os meridianos $34^{\circ} 48^{\prime} 35^{\prime}$ "

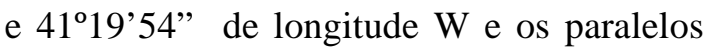
$7^{\circ} 15^{\prime} 45^{\prime \prime}$ e $9^{\circ} 28^{\prime} 18^{\prime \prime}$ de latitude S. A partir de variações morfopedológicas, geológicas, altitudinais, florísticas e vegetacionais, AndradeLima (1960) dividiu o estado em quatro zonas fitogeográficas, a saber: do Litoral, da Mata, das Caatingas e das Savanas.

\section{Estudos de campo e laboratório}

Foram realizadas excursões a várias localidades do estado de Pernambuco, entre abril de 1999 e agosto de 2000; incluindo municípios dos estados da Paraíba e Sergipe. As coletas de material botânico e o processamento das coleções foram procedidos de acordo com a metodologia usual em taxonomia vegetal (Bridson \& Forman, 1998). As coleções obtidas foram depositadas no Herbário Professor Vasconcelos-Sobrinho (PEUFR). As descrições foram elaboradas seguindo-se as terminologias propostas por Lawrence (1951) e Radford et al. (1974). Payne (1978) e Hickey (1973) foram verificados para a caracterização dos padrões de indumento e venação, respectivamente.

Para cada espécie apresenta-se uma descrição acompanhada da relação do material examinado, além de comentários sobre afinidades taxonômicas e dados sobre a distribuição geográfica dos taxa. São fornecidas ainda chave de reconhecimento e ilustrações, além de mapa de distribuição das espécies ocorrentes na área estudada (Fig. 59). Nomes comuns são fornecidos para algumas espécies; os mesmos foram registrados nos sítios de coleta e através de etiquetas de herbários.A identidade dos taxa e o tratamento infragenérico foram baseados, fundamentalmente, em Johnston (1928) e Förther (1998).

O estudo foi complementado pela análise de exsicatas recebidas por empréstimo e/ou doação de diferentes herbários nacionais: ALCB, ASE, BHMH, CEN, CH,CPAP, CPAP, CPATU, CVRD, ESA, FUEL, GUA, HAS, HEPH, HFC, HRCB, HST*, HUEFS, HUFU, IAC, IPA, JPB, MAC, PACA, PEL, R, RB, SJRP, SP, SPF, SPSF, UB, UFMT, UFP e VIC; cujos acrônimos estão de acordo com Holmgren et al. (1990).

\section{RESULTADOS E DISCUSSÃO}

\section{Morfologia de Heliotropium L. ocorrente em Pernambuco - Nordeste do Brasil}

Hábito

O hábito em Heliotropium é predominantemente herbáceo, ocorrendo também subarbustivo e mais raramente arbustivo (Gentry, 1993). Os representantes deste gênero ocorrentes no estado de Pernambuco apresentam-se como ervas e subarbustos, apenas $H$. polyphyllum mostrase exclusivamente herbáceo.

São plantas eretas ou mais freqüentemente decumbentes ou prostradas, em geral bastante ramificadas, com ramos longos sobre o solo, como ocorre em vários indivíduos de Heliotropium procumbens e $H$. polyphyllum. Os ramos são cilíndricos ou angulosos e fistulosos, como em Heliotropium elongatum e $H$. indicum, e geralmente indumentados. A coloração pode apresentarse esverdeada ou acinzentada, em $H$. procumbens.

* Não encontra-se listado no Index Herbariorum (Holmgren et al., 1990) -Herbário Sérgio Tavares, Departamento de Engenharia Florestal Universidade Federal Rural de Pernambuco, Recife, PE, Brasil. 


\section{Indumento}

No gênero Heliotropium, de acordo com Akhani \& Förther (1994), o indumento apresenta-se bastante variado em relação à altitude onde a planta ocorre. Em áreas de baixa altitude e de clima quente, as espécies exibem tricomas patentes; enquanto em áreas mais elevadas e de clima frio, estes são adpressos.

As espécies abordadas neste estudo mostram indumento diversificado, exibindo, em geral, diferentes tipos, tanto nas estruturas vegetativas, como nas reprodutivas. Variam de totalmente glabras, como em H.curassavicum, ou seríceas com tricomas esbranquiçados revestindo todas as estruturas vegetativas e florais, em $H$. procumbens. Tricomas curtos intercalados por tricomas longos e adpressos são encontrados na face adaxial de $H$. elongatum e $H$. indicum, sendo que nesta última espécie, os longos são maiores (aciculiformes) e com uma base discóide.

\section{Folha}

As folhas são geralmente alternas ou menos frequientemente opostas, simples, sésseis a longamente-pecioladas em $H$. procumbens (Fig. 41), sem estípulas. Em algumas espécies, apresentam-se alternas e subopostas a opostas no mesmo indivíduo, especialmente próximas as bifurcações dos ramos. São sempre alternas em $H$. polyphyllum e $H$. procumbens, $H$. ternatum e apenas opostas em $H$. curassavicum.

O pecíolo é cilíndrico a subcilíndrico e sulcado na face superior, em $H$. procumbens, glabrescente a indumentado, parcialmente alado em Heliotropium elongatum e $H$. indicum. O tamanho das folhas nas espécies abordadas neste estudo é pouco variável. A lâmina é sempre inteira. A forma apresenta-se de estreitamenteespatulada a linear, em $H$. curassavicum e de lanceolada a linear, em $H$. ternatum ou ovais, elípticas a cordiformes nas demais espécies. A textura da lâmina foliar é membranácea na maioria das espécies, sendo cartácea a subcoriácea, em $H$. polyphyllum e $H$. ternatum ou subcarnosa, em $H$. curassavicum. A base pode ser atenuada, cuneada a aguda, truncada e, às vezes, assimétrica em $H$. indicum (Fig. 24). $\mathrm{O}$ ápice apresenta-se geralmente agudo a acuminado, sendo arredondado em $H$. curassavicum e mucronado em $H$. procumbens. A margem é geralmente inteira, plana a erosa em Heliotropium indicum e revoluta, em $H$. ternatum. O padrão de venação apresenta-se geralmente camptódromo-eucamptódromo, na maioria das espécies, e reticulódromo como em Heliotropium polyphyllum e H. ternatum.

\section{Inflorescência}

Os representantes da família Boraginaceae, segundo Barroso et al. (1994), se caracterizam pela constância de inflorescências monotélicas. Para o gênero Heliotropium, estas autoras relatam que as inflorescências são cimas, levemente ou acentuadamente escorpióides, resultantes de ramos que concresceram entre si, apresentando as flores mais desenvolvidas na base e as mais jovens no ápice. Nas espécies estudadas, as inflorescências são geralmente axilares e subterminais ou terminais, bracteadas (Figs. 33 e 41) ou não, pedunculadas, laxas ou mais freqüentemente congestas. Podem ser longas, atingindo $28 \mathrm{~cm}$ de comprimento em $H$. indicum ou curtas, menores de $1 \mathrm{~cm}$, multifloras ou paucifloras, às vezes reduzidas a 2-3 flores em H.curassavicum (Figs. 9 e 10). Estas podem se apresentar inteiras ou bifurcadas, em $H$. angiospermum e $H$. procumbens (Fig. 41) ou, ainda, em número de 2 a 4 partindo de um mesmo ponto. A raque é achatada e varia de glabra, em $H$. curassavicum, a serícea em $H$. procumbens e $H$. ternatum. O pedúnculo é cilíndrico, glabro ou indumentado.

As brácteas estão presentes apenas em Heliotropium polyphyllum (Fig. 35 ) e $H$. ternatum (Fig. 50), sendo uma por cada flor. Estas são ovais com venação reticulódroma em $H$. polyphyllum e estreito-elípticas em H. ternatum.

\section{Flor}

As flores em Heliotropium são sésseis a curtamente-pediceladas, andróginas, simpétalas, pentâmeras e levemente zigomorfas. Quando 
presente o pedicelo é cilíndrico, glabro a indumentado e com até $1 \mathrm{~mm}$ de comprimento, como em $H$. curassavicum (Fig. 12) e $H$. ternatum (Fig. 53). O cálice é gamossépalo, em geral profundamente lobado, ou com as sépalas unidas por dois terços do seu comprimento, em H. curassavicum. $\mathrm{Na}$ maioria das espécies, apresenta-se persistente no eixo da inflorescência após a queda do fruto, com exceção de $H$. polyphyllum no qual é persistente no fruto e desprende-se junto com este. Os lobos exibem tamanhos ligeiramente diferentes, indo de estreitamente-oblongos a estreitamente-lanceolados até estreitamenteovais a oval-lanceolados.

A corola é gamopétala, hipocrateriforme ou tubular-hipocrateriforme em $H$. curassavicum, $H$. procumbens e H. ternatum. O tubo, na maioria das espécies, é cilíndrico afunilando-se para o ápice e constricto na fauce; apenas em $H$. ternatum o tubo apresenta duas constrições, uma próxima a base e outra próxima a fauce. $\mathrm{O}$ limbo mostra-se com a porção basal unida e pouco a profundamente lobado em H. ternatum. A coloração varia de branca a arroxeada com a fauce amarela, na maioria das espécies e é amarela somente em H. polyphyllum. A corola é, em geral, indumentada externamente e com um anel de tricomas internamente, logo abaixo da fauce.

$\mathrm{O}$ androceu é constituído por cinco estames, sésseis a subsésseis, inclusos, epipétalos, alternos aos lobos da corola, e inseridos, na maioria das espécies, na porção mediana do tubo ou próximos à base do tubo na altura da constrição basal em $H$. ternatum. A forma das anteras varia de oval a ovallanceolada, com o ápice distintamente apiculado em $H$. angiospermum ou caudado a longocaudado em $H$. polyphyllum (Fig. 34) e $H$. ternatum (Fig. 54). É interessante mencionar, que nestas duas últimas espécies os ápices das anteras são coerentes, sendo levemente em $H$. polyphyllum e fortemente em $H$. ternatum.

$\mathrm{O}$ ovário é súpero, em geral globoso a subgloboso, ou profundamente 4-sulcado em $H$. polyphyllum (Fig. 38). É sempre bicarpelar, às vezes com carpelos divididos longitudinalmente ao meio por um falso septo, formando uma estrutura pseudo-tetracarpelar. O número de óvulos varia de 2 por lóculo, no ovário bilocular, ou 1 por lóculo, quando tetralocular após a formação do falso septo. Os nectários são intraflorais, localizando-se na base do ovário, em forma de disco (Al-Nowaihi et al., 1987). O estilete é cilíndrico e indiviso e nas espécies estudadas pode ser inconspícuo (Figs. 6 e 14), ou nunca ultrapassando $0,5 \mathrm{~mm}$ de comprimento.

O estigma em Heliotropium é uma estrutura especializada. É constituído por uma porção superior estéril, cônica, umbraculiforme, capitada a penicilada e uma porção basal aneliforme, de espessura variável dependendo da espécie, formada pelo tecido estigmático. Gangui (1955), observa que as estruturas estigmáticas têm relevância na sistemática do gênero Heliotropium; tal observação também foi corroborada neste trabalho.

\section{Fruto}

Nas espécies de Heliotropium o fruto é esquizocarpáceo, separando-se em mericarpos drupóides (Barroso et al., 1999). Os mericarpos podem ser em número de 2 , com 2 sementes cada ou em número de 4, com uma semente cada. Em geral os mericarpos são designados pela grande maioria dos estudiosos (Johnston, 1928; Gangui, 1955; Akhani \& Förther, 1994) deste gênero como núculas. O número de núculas e sementes, bem como a forma e a superfície são caracteres utilizados desde os primeiros trabalhos abordando a taxonomia de Heliotropium, como De Candolle (1845), Fresenius (1857/1863) e Bentham \& Höoker (1876).

Na maioria das espécies estudadas, o fruto é constituído por 4 núculas com uma única semente, somente $H$. angiospermum (Fig. 7) e H. elongatum (Fig. 21) apresentam fruto constituído por duas núculas com duas sementes cada. A forma é em geral globosa a subglobosa, mitriforme em $H$. elongatum, ou trifacetadas em $H$. polyphyllum (Fig. 39), $H$. procumbens (Fig. 47) e H. ternatum (Fig. 57). 
Para a maioria das espécies apresentam-se glabros, sendo hirsutos em $H$. procumbens e H. ternatum. Vale salientar que a superfície em $H$. angiospermum é geralmente revestida por apêndices vesiculares.

\section{Semente}

As sementes são achatadas, apresentando-se geralmente elipsóides, ou às vezes trifacetadas a triangulares em Heliotropium polyphyllum (Fig. 40). Geralmente muito pequenas, variam de 1 a 3,5 $\mathrm{mm}$ de comprimento em Heliotropium elongatum (Fig. 23).

\section{Tratamento taxonômico}

Heliotropium L., Syst. ed. I: 1735. Espécie-tipo: H. europaeum L.
Ervas a subarbustos, raramente arbustos, anuais ou perenes. Folhas alternas a subopostas, raramente opostas a subverticiladas, sésseis ou pecioladas, simples; lâmina membranácea a subcarnosa, glabra a indumentada, venação camptódroma, eucamptódroma a reticulódroma. Cimas terminais ou axilares, escorpióides, solitárias ou às vezes 2-4 agrupadas, pedunculadas, bracteadas ou não. Flores sésseis ou pediceladas. Cálice gamossépalo, 5lobado. Corola simpétala, pentâmera, infundibuliforme ou hipocrateriforme, lilás a violeta até purpúrea, às vezes branca ou menos frequientemente amarela, fauce freqüentemente pubescente; lobos orbiculares a suborbiculares, até ovais ou deltóides, margem em geral ondulada. Estames inclusos, sésseis ou com filetes curtos; anteras dorsifixas e introrsas,

\section{CHAVE PARA O RECONHECIMENTO DAS ESPÉCIES DE HELIOTROPIUM OCORRENTES EM PERNAMBUCO}

1. Inflorescências com brácteas; estames com anteras de ápice coerente (levemente unidas entre si)

2. Lâmina foliar de margem revoluta; flores alvas com fauce amarela; brácteas 2,5-2,7 x 0,3$0,4 \mathrm{~mm}$, estreitamente-elípticas

2'. Lâmina foliar de margem plana; flores amarelas; brácteas 3-4 x 1-1,3 mm, ovais

5. H. polyphyllum

1'. Inflorescências sem brácteas; estames com anteras de ápice livre entre si

3. Folhas sésseis, de estreitamente-espatuladas a lineares; inflorescência 0,7-2,5 cm compr., distintamente escorpióide ou reduzida a 2 a 3 flores

2. H. curassavicum

3'. Folhas pecioladas, ovais a oval-elípticas, oval-cordiforme ou oval-deltóide, elíptica, rômbica, estreitamente-elíptica a oblonga; inflorescência 1-28 cm compr., distintamente escorpióide 4. Pecíolo parcialmente alado; gineceu com estilete evidente

5. Lâmina foliar com face adaxial bulada; cálice menor que a metade do comprimento da corola; fruto constituído por 2 núculas, com duas sementes cada; núculas com 5-7 nervuras salientes, ápice levemente bidenticulado 3. H. elongatum

5'. Lâmina foliar com face adaxial plana; cálice maior que a metade do comprimento da corola; fruto constituído por 4 núculas, com 1 semente cada; núcula com 2-3 nervuras salientes, ápice acentuadamente bidentado 4. H. indicum

4'. Pecíolo nunca alado; gineceu com estilete nulo ou inconspícuo

6. Indumento seríceo revestindo ramos, folhas e lores; corola empre branca, fauce amarela; anteras com ápice caudado; núculas 4 , hirsutas 6. H. procumbens

6'. Indumento escabro a estrigoso revestindo ramos e pubescente cobrindo ambas as faces da lâmina foliar; corola branca a arroxeada, fauce amarela; anteras com ápice apiculado; núculas 2, testa revestida por apêndices vesiculares 1. H. angiospermum 
ovais a lineares. Ovário 2-locular ou falsamente 4-locular; óvulos 2 por lóculo, ou 1 quando falsamente 4-locular; estilete terminal, cilíndrico; estigma cônico ou umbraculiforme, com a base espessada em anel, séssil ou subséssil. Fruto esquizocarpáceo, separando-se em 2 núculas com 2 sementes ou em 4 núculas com uma semente cada. Sementes planas ou curvas, geralmente com um endosperma delgado, amarelo a verde-claro.

$\mathrm{Na}$ área de estudo, verificou-se a ocorrência de sete espécies acomodadas em quatro seções:

I - Heliotropium sect. Schobera (Scop.) I.M. Johnst.:

1. H. angiospermum Murray;

II - Heliotropium sect. Platygyne Benth.:

2. H. curassavicum L.;

III - Heliotropium sect. Tiaridium (Lehm.) Griseb:

3. H. elongatum (Lehm.) I.M. Johnst.;

4. H. indicum $\mathrm{L}$.

IV - Heliotropium sect. Orthostachys R.Br.:

5. H. polyphyllum Lehm.;

6. H. procumbens Mill.;

7. H. ternatum Vahl

\section{Descrição dos taxa}

1. Heliotropium angiospermum Murray, Prodr. stirp. Gott.: 217. 1770.

Figs. 1-8.

Erva ou subarbusto, 0,2-1 m alt., ereto ou subereto. Ramos cilíndricos, de escabros a estrigosos. Folhas alternas a subopostas, algumas vezes opostas no mesmo indivíduo, pecioladas; pecíolo 0,2-1,2 cm compr.; lâmina $0,8-9,8 \times 0,4-4,8 \mathrm{~cm}$, membranácea, oval a elíptica, base atenuada, ápice agudo a acuminado, margem inteira, faces abaxial e adaxial pubescentes; venação eucamptódroma. Inflorescência 1,8-24,5 cm compr., subterminal e axilar, laxa a congesta, inteira ou bifurcada, pedunculada, não bracteada; pedúnculo 2-4,5 cm compr. Flores 2,3-3,5 mm compr., sésseis. Cálice profundamente lobado, persistente no eixo da inflorescência após a queda do fruto; lobos 1,8-3,2 x 0,5-0,7 mm, estreito-oblongos, margem ciliada, pubescentes externa e internamente. Corola 3-3,5 mm compr., hipocrateriforme, branca a arroxeada, fauce amarela, externamente pubescente; tubo 2,22,5 mm compr., subcilíndrico, afunilado para o ápice, internamente piloso na altura da fauce; lobos orbiculares. Estames subsésseis, inseridos a $0,8 \mathrm{~mm}$ acima da base do tubo da corola; anteras 0,8-1,2 mm compr., oval-oblongas, base subcordada, ápice apiculado, livre. Ovário ca 0,5 mm compr., subgloboso, 2-locular; estilete inconspícuo, inteiramente recoberto pelo estigma; estigma ca. $0,8 \mathrm{~mm}$ compr., umbraculiforme; óvulos 2 por lóculo, curvos. Fruto 2-3 mm diâm., subgloboso; núculas 2, com testa geralmente revestida por apêndices vesiculares, marrom-acinzentado. Sementes 2 por núcula, ca. $1 \mathrm{~mm}$ compr., largo-ovais, amarelo-esverdeadas, rugosas.

Distribuição geográfica: A espécie apresenta-se distribuída do sul dos Estados Unidos (Texas e Flórida) e México até Brasil e Chile, incluindo Antilhas (Fröhlich in Nash \& Moreno [1981]). Gibson (1970) observa que esta espécie é bastante freqüente em várias regiões baixo-montanas da América Central, onde é invasora. No Brasil, encontra-se distribuída nas regiões Nordeste (AL, BA, CE, PB, PE e SE) e Sudeste (RJ). Em Pernambuco, Heliotropium angiospermum apresenta-se amplamente distribuída, desde a zona do Litoral até a zona das Caatingas e na ilha de Fernando de Noronha, preferencialmente em áreas abertas; em geral antropizadas ou em margens de estradas: tanto em solos arenosos como argilosos ou mais raramente em afloramentos rochosos.

Comentários: O exemplar-tipo de Heliotropium angiospermum é desconhecido. Segundo Fröhlich apud Nash \& Moreno (1981), o tipo foi obtido a partir de uma planta cultivada em jardins botânicos europeus. Johnston (1928) reconhece para esta espécie 14 sinônimos, destacando-se Heliophytum parviflorum, binômio adotado por De Candolle (1845) e posteriormente por Fresenius (1857), na Flora Brasiliensis. 


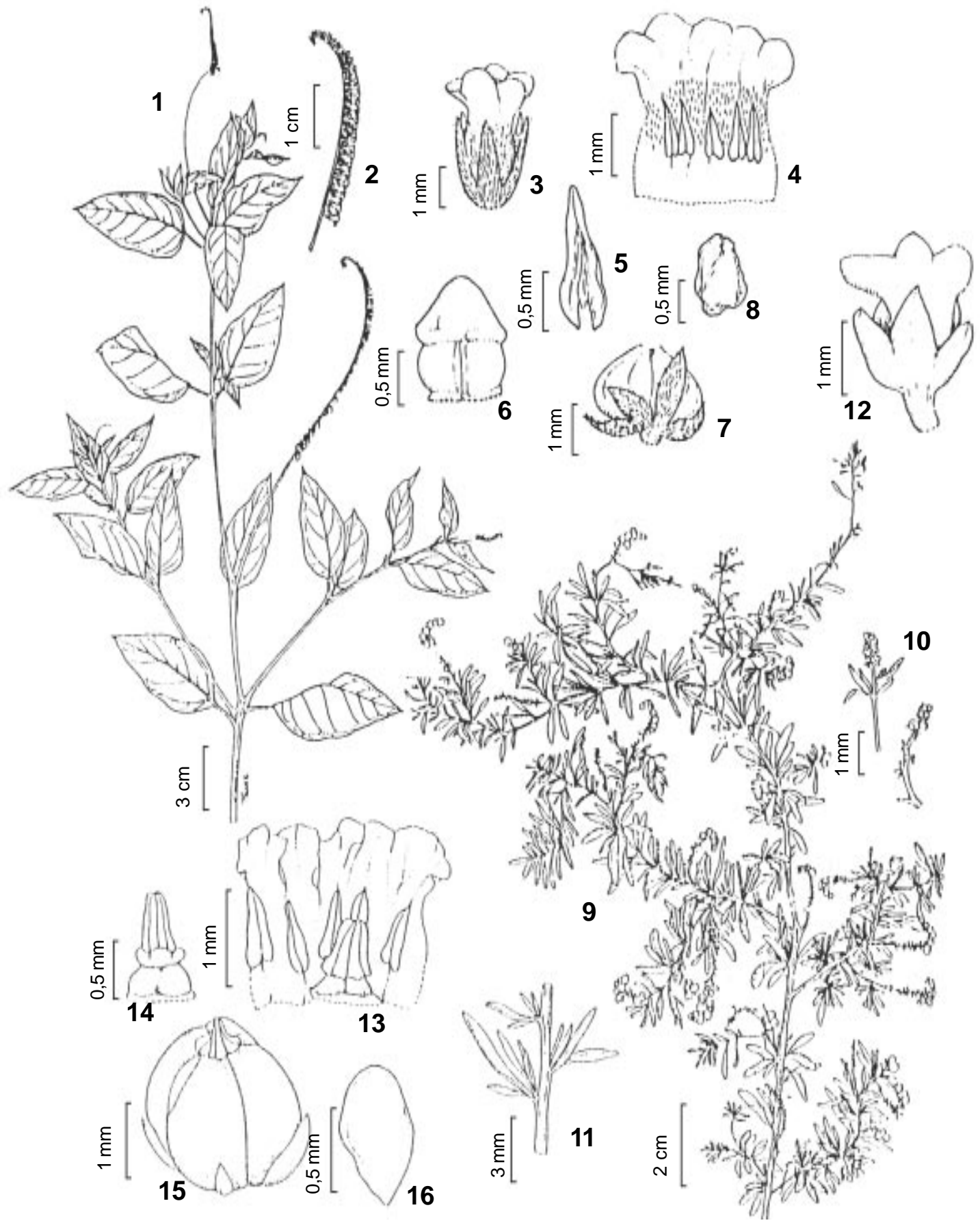

Figuras 1-16: Heliotropium angiospermum Murray (Melo 399): 1-8. 1. Aspecto geral do ramo; 2. Detalhe da inflorescência; 3. Flor; 4. Corola aberta; 5. Estame; 6. Gineceu; 7. Fruto, com cálice persistente; 8. Semente, vista frontal (Melo 242 ); $H$. curassavicum L. (Sales 13): 9-16. 9. Aspecto geral do ramo; 10. Detalhe da inflorescência; 11. Detalhe do ramo, evidenciando folhas; 12. Flor; 13. Corola aberta; 14. Gineceu; 15. Fruto; 16. Semente. 
A espécie apresenta afinidades com Heliotropium transalpinum Vell. (com distribuição da Bahia até o Rio Grande do Sul), separando-se desta pela ausência de tricomas malpighiáceos, pelos estames subsésseis inseridos próximos à base do tubo da corola $\mathrm{e}$ especialmente pelos lobos do cálice menores bem como pelo fruto que apresenta-se geralmente recoberto por apêndices vesiculares de coloração marrom-acinzentado. Verificouse que em alguns indivíduos coletados em Garanhuns, a superfície do fruto apresenta-se desprovida desses apêndices. O mesmo foi observado por Johnston (1928), comentando que a ausência desses apêndices só foi constatada em materiais provenientes do Brasil. Material examinado selecionado: Brasil. Pernambuco: Alagoinha, 20.VII.1999, U.P. Albuquerque et al. 267, fl. (UFP); Ameixas, 14.VIII.2000 , J.I.M. Melo 377, fl., fr. (PEUFR); Arcoverde, 29.VI.2000 , J.I.M. Melo 333, fl., fr. (PEUFR); Belo Jardim, 14.X.1970, J.L.H. Alves 37, fl. (UFP); Bezerros, 17.XII.1999, J.I.M. Melo 207, fl., fr. (PEUFR); Brejão, 17.II.2000, J.I.M. Melo 233, fl., fr., J.I.M. Melo 233 (PEUFR); Cachoeirinha, 14.VIII.2000, J.I.M. Melo 382, fl., fr. (PEUFR); Calçado, 14.VIII.2000, J.I.M. Melo 388, fl., fr. (PEUFR); Caruaru, 18.XII.1999, J.I.M. Melo 212, fl., fr. (PEUFR); Cumaru, 14.VIII.2000, J.I.M. Melo 376, fl., fr. (PEUFR); Garanhuns, 16.II.2000, J.I.M. Melo 225, fl., fr. (PEUFR); Gravatá, 17.XII.1999, J.I.M. Melo 204, fl., fr. (PEUFR); Ilha de Fernando de Noronha, 8.IV.1999, A.M. Miranda 3224 (HST), fl., fr. (HST); Jupi, 5.IV.1999, J.I.M. Melo 120, fl., fr. (PEUFR); Lajedo, 14.VIII.2000, J.I.M. Melo 385, fl., fr. (PEUFR); Limoeiro, IV.1937, Vasconcelos-Sobrinho s.n., fl. (RB 93677), Passira, 14/8/2000, J.I.M. Melo 375, fl., fr. (PEUFR); Paudalho, 20.III.2000, J.I.M. Melo 241, fl., fr. (PEUFR); Paulista, X.1991, L.C. Gomes 204, fl., fr. (PEUFR); Pesqueira, 29.VI.2000, J.I.M. Melo 330, fl., fr. (PEUFR); Quipapá, 12.I.1994, A.M. Miranda 1183, fl., fr. (PEUFR); Recife, 20.VIII.1990, R.M.
Nascimento 01, fl., fr. (PEUFR); Riacho das Almas, 14.VIII.2000, J.I.M. Melo 378, fl., fr. (PEUFR); Santa Maria da Boa Vista, 29.IV.1971, E.P. Heringer et al. 384, fl., fr. (UB); São Caitano, 29.VI.2000, J.I.M. Melo 327, fl., fr. (PEUFR); Serra Talhada, 17.IV.197, E.P. Heringer et al. 22, fl., fr. (UB); Taquaritinga do Norte, 12.V.2000, J.I.M. Melo 279, fl., fr. (PEUFR); Triunfo, 10.III.1995, A.M. Miranda 2117, fl., fr. (HST); Vertentes, 11.V.2000, J.I.M. Melo 267, fl., fr. (PEUFR); Vicência, 20.III.2000, J.I.M. Melo 246, fl., fr. (PEUFR); Vitória de Santo Antão, 17.XII.1999, J.I.M. Melo 203, fl., fr. (PEUFR).

Material adicional: Brasil. Bahia: Castro Alves, 12.XI.1983, G.C. Pereira Pinto et al. 384, fl., fr. (RB); Feira de Santana, 21.VII.1987, L.P. de Queiroz et al. 1725, fl., fr. (HUEFS); Itatim, morro da quixaba, 15.XII.1996, E. Melo et al. 1910, fl., (HUEFS); Jacobina, 28.VI.1983, L. Coradin et al. 6155, fl., fr. (CEN); Santa Bárbara, 30.I.1980, L.R. Noblick s.n., fl., fr. (HUEFS 1644); Santa Luz, 07.VII.1976, A. Rocha s.n., fl., fr. (IAC 23255); Ceará: Canindé, 15.VI.1979, L. Coradin et al. 1970, fl., fr. (CEN); Olho d'Água do Vieira, 18.VII./1961, S. Tavares 664, fl., fr. (HST); Paraíba: Areia, 20.IV.1956, J.M. Vasconcelos s.n., fl. (SPSF 2537); Rio de Janeiro: Rio de Janeiro, 18.X.1947, O. Machado s.n., fl. (GUA 18641); Sergipe: Canindé do São Francisco, 05.V.2000, J.I.M. Melo 262, fl., fr. (PEUFR); Itabi, 27.VIII.1982, E. Gomes 55, fl., fr. (ASE).

Equador. Chimborazo: Huigra, 22.II.1955, E. Asplund 15521, fl., fr. (R); Esmeraldas: Santo Domingo de los Colorados, 16.V.1955, E. Asplund 16381, fl. (R); Guayas: Zapotal, 08.V.1959, G. Harling s.n., fl., fr. (R 197.164).

2. Heliotropium curassavicum L., Sp. Pl. 1: 130. 1753.

Figs. 9-16.

Erva ou subarbusto, $10-20 \mathrm{~cm}$ alt., prostrado, em geral bastante ramificado. Ramos cilíndricos, amarronzados, glabros. Folhas opostas ou subopostas, sésseis; lâmina 0,7-1,3 
x 0,1-0,4 cm, subcarnosa, oblanceolada, de estreitamente-espatulada a linear, base cuneada, ápice arredondado, margem inteira, glabra; venação reticulódroma. Inflorescência 0,7-2,5 cm compr., axilar e subterminal, sem brácteas, em geral em ramos curtos, distintamente escorpióide ou reduzida a 2-3 flores, curtopedunculada, não bracteada; pedúnculo $0,2-0,5$ $\mathrm{mm}$ compr. Flores 2-2,2 mm compr., sésseis a curtamente-pediceladas. Cálice 1,5-2 mm compr., sépalas unidas por $2 / 3$ do seu comprimento, persistente no eixo da inflorescência após a queda do fruto; lobos 11,2 x 0,4-0,5 mm, estreitamente-ovais. Corola 2-2,2 x 0,7-0,8 mm, tubular-hipocrateriforme, branca, glabra interna e externamente; tubo 1,11,2 mm compr., subcilíndrico estreitando-se em direção à fauce; lobos $0,5-0,6 \mathrm{~mm}$ compr., orbiculares. Estames sésseis, inseridos $0,5 \mathrm{~mm}$ acima da base do tubo da corola; anteras ca. 0,8 mm compr., ovais, base cordada, ápice agudo, livre. Ovário ca 0,3 mm compr., globoso, 4-locular, glabro; estilete inconspícuo, recoberto pelo estigma; estigma cônico, ca. $0,7 \mathrm{~mm}$ compr., estriado longitudinalmente; óvulo 1 por lóculo. Fruto 1-2 mm diâm., globoso; núculas 4, separando-se completamente na maturação, testa lisa. Semente 1 por núcula, até $1 \mathrm{~mm}$ compr., estreito-elípticas, carnosas, amarronzadas.

Distribuição geográfica: Heliotropium curassavicum apresenta distribuição nas regiões tropicais das Américas (do sul dos Estados Unidos até Argentina) bem como na África e Ásia (Johnston, 1928), exclusivamente halófila. De acordo com Akhani \& Forther (1994), a espécie parece ser nativa das Américas e ter sido introduzida nos demais continentes. No Brasil, é citada para São Paulo e Rio Grande do Sul (Johnston, 1928). Está sendo referida pela primeira vez para o Nordeste, nos estados de Pernambuco e Paraíba. Em Pernambuco, foi encontrada apenas no município de Afrânio; na Paraíba nas margens salinas do açude de Soledade, nos Cariris Velhos.

Comentários: Heliotropium curassavicum é facilmente identificada por ser completamente prostrada e glabra, com folhas sésseis, subcarnosas, lineares a estreito-espatuladas e pelo fruto globoso. Segundo Akhani \& Förther (1994), foi escolhido como lectótipo uma ilustração da planta confeccionada por Morison em 1699.

Material examinado: Brasil. Paraíba: Soledade, 23.XI.1984, M. Sales 13, fl., fr. (PEUFR); ibidem, 13.III.1986, M. Sales et al. 44, fl., fr. (PEUFR); Pernambuco: Afrânio, 1984, R. Pereira s.n., fl., fr. (IPA 49852).

3. Heliotropium elongatum (Lehm.) I.M. Johnst., Contr. Gray Herb. Harv. Univ. 81: 18. 1928.

Tiaridium elongatum Lehm. Asperifolien 1: 16. 1818; Ícones 10. t. 6. 1821

Figs. 17-23.

Erva ou subarbusto, $10-90 \mathrm{~cm}$ alt., ereto ou decumbente. Ramos angulosos, fistulosos, esparso a densamente hirsutos. Folhas alternas, ou às vezes subopostas, pecioladas; pecíolo 0,65,7 cm compr., parcialmente alado; lâmina 2$12,5 \times 1,2-7,8 \mathrm{~cm}$, membranácea, oval a cordiforme, deltóide, base assimétrica, truncada, ápice agudo a acuminado, margem inteira, face adaxial fraca a fortemente bulada, escabra a glabrescente, com tricomas curtos intercalados por tricomas longos e adpressos, face abaxial pubescente, com tricomas curtos intercalados por longos e esparsos; venação eucamptódroma. Inflorescência $2-12 \mathrm{~cm}$ compr., subterminal e axilar, pedunculada, não bracteada; pedúnculo $2-4 \mathrm{~cm}$, pubescente, com tricomas curtos entremeados com longos e esparsos. Flores 3-5 mm compr., sésseis. Cálice 2-2,8 x 0,4-0,5 mm compr., profundamente lobado, menor que a metade do comprimento do tubo da corola, persistente no eixo da inflorescência após queda do fruto, com tricomas longos aciculiformes, especialmente nas margens; lobos 1,8-2,5 x 0,3-0,5 mm, lanceolados. Corola 5-6,5 mm compr., hipocrateriforme, branca a arroxeada, externamente e internamente pubescente; tubo 2,6-4,2 mm compr., subcilíndrico, estreitandose para o ápice; lobos $0,5 \mathrm{~mm}$ compr., 

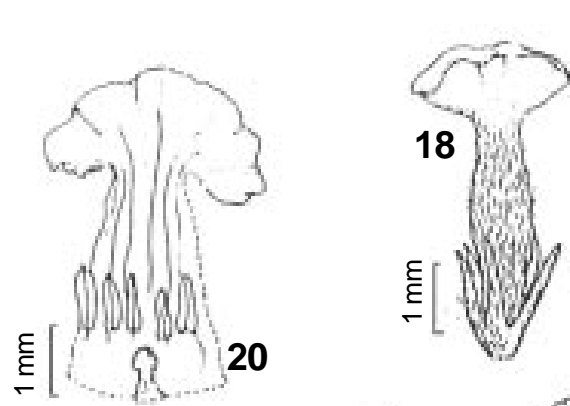

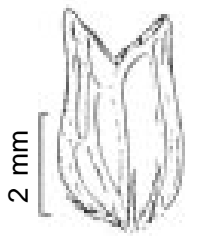

21
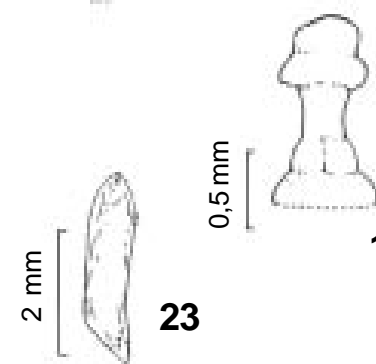

19

23
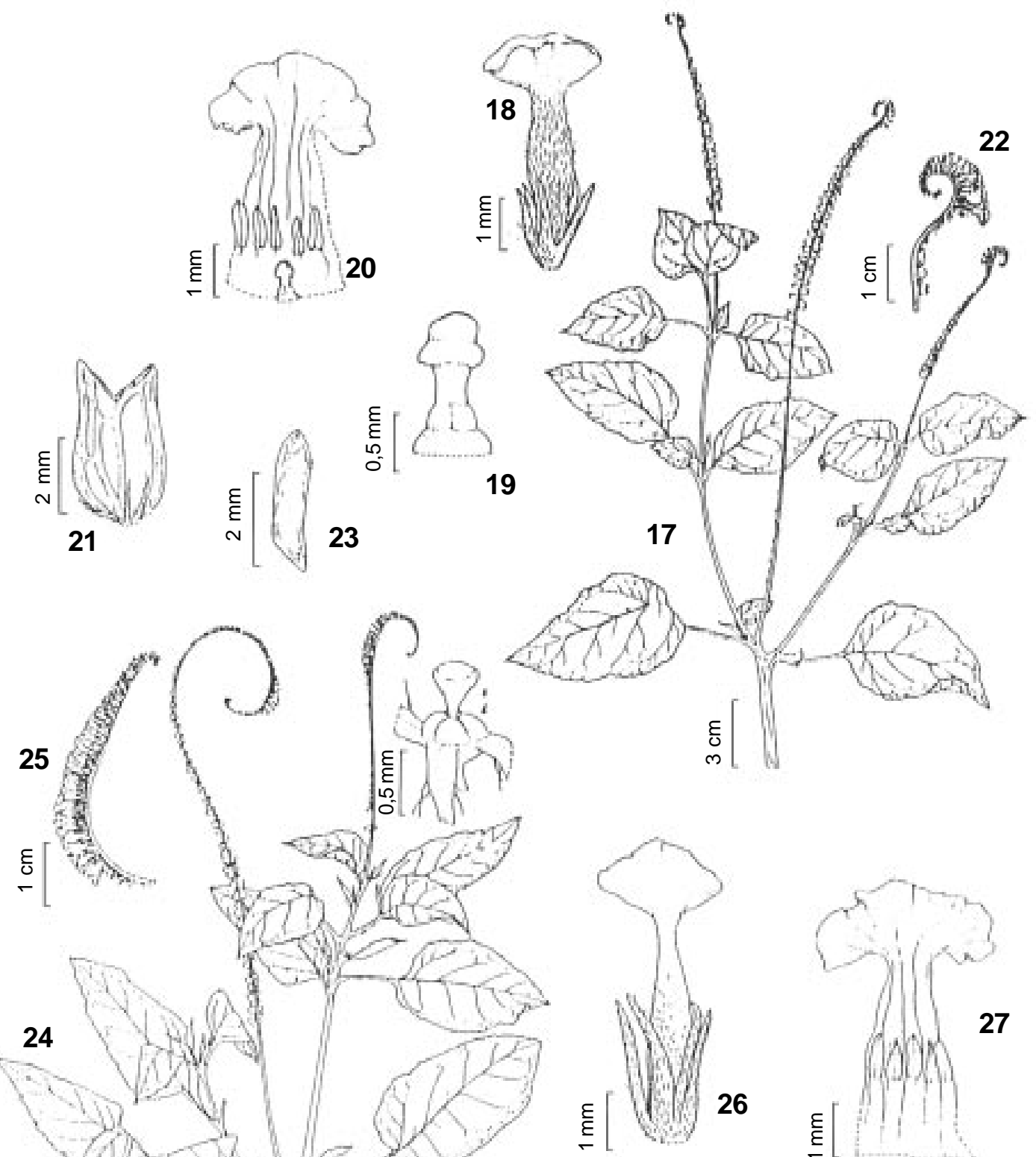

26
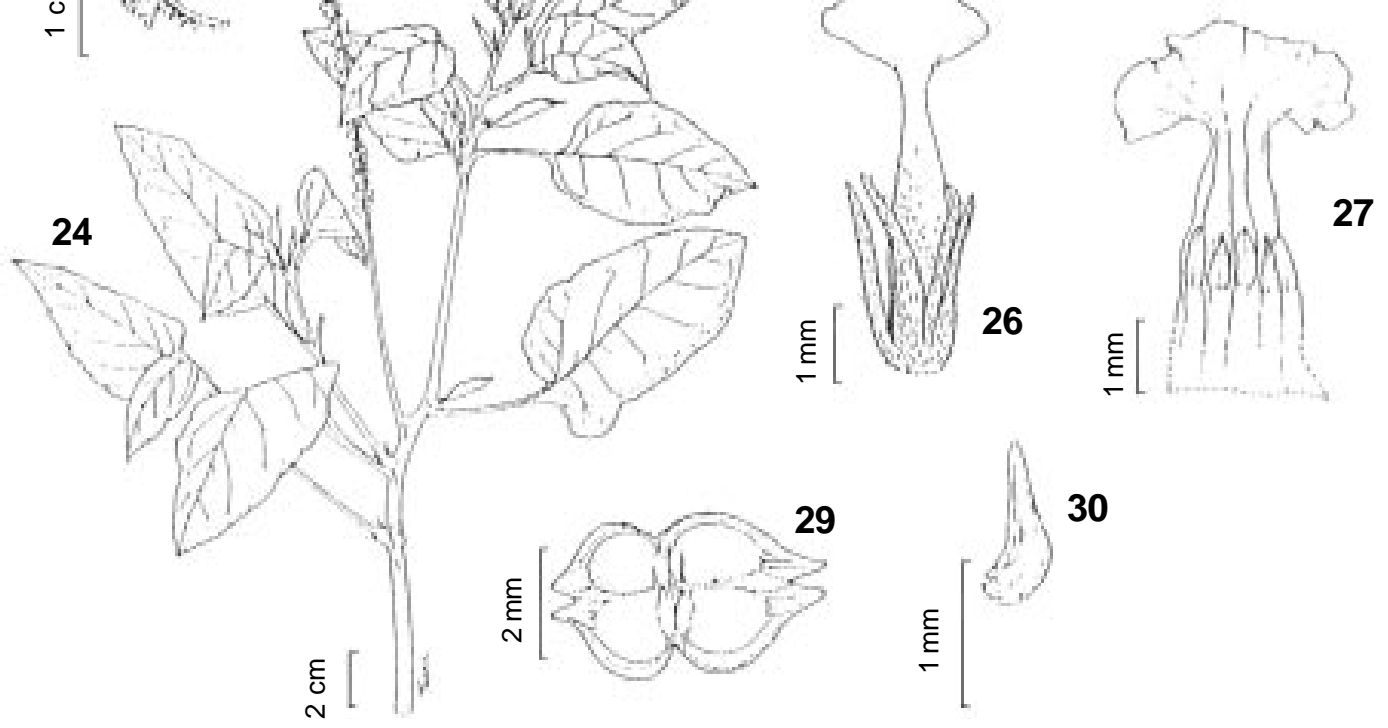

Figuras 17-30: Heliotropium elongatum (Lehm.) I.M. Johnst. (Melo 237): 17-23. 17. Aspecto geral do ramo; 18. Flor; 19. Gineceu; 20. Corola aberta; 21. Fruto; 22. Detalhe da inflorescência; 23. Semente, vista frontal (Melo 196); H. indicum L.: 24-30. 24. Aspecto geral do ramo; 25. Detalhe da inflorescência; 26. Flor; 27. Corola aberta; 28. Gineceu; 29. Fruto; 30. Semente, vista dorsal. 
orbiculares. Estames sésseis a subsésseis, inseridos 0,8-1,5 $\mathrm{mm}$ acima da base do tubo da corola; anteras ca. $1 \mathrm{~mm}$ compr., estreitamenteoblongas, ápice retuso. Ovário ca. 0,5 mm compr., globoso, 2-locular; estilete evidente, ca. 0,5 mm compr.; estigma $0,2 \mathrm{~mm}$ compr., campanulado invertido; óvulos 2 por lóculo, achatados. Fruto 2-2,5 mm diâm., mitriforme; núculas 2, com 5-7 nervuras salientes na face dorsal, ápices levemente bidenticulados, glabras. Sementes 2 por núcula, 3-3,5 mm compr., trígonas, amarronzadas, lisas.

Distribuição geográfica: Heliotropium elongatum é uma espécie com distribuição exclusiva na América do Sul Oriental (Argentina, Bolívia, Brasil, Paraguai e Uruguai), de acordo com Johnston (1928). No Brasil, H. elongatum está distribuída nas regiões Nordeste (BA, CE, MA, PB, PE, PI, RN e SE), Centro-oeste (MS e MT), Sudeste (MG, RJ e SP) e Sul (RS), sendo referida para ambientes abertos. Em Pernambuco, a espécie apresenta ampla distribuição, ocorrendo desde a zona do Litoral até a zona das Caatingas e no arquipélago de Fernando de Noronha, em áreas abertas.

Comentários: De acordo com Johnston (1928), a coleção-tipo de Heliotropium elongatum é proveniente do Brasil, sem localidade definida, coletada por Sellow s/n, cujo holótipo está depositado, provavelmente, no herbário B e um isótipo no Kew. Os caracteres mais relevantes para o reconhecimento de $H$. elongatum são encontrados no ovário 2-locular, com 2 óvulos por lóculo e especialmente no fruto com as núculas de ápice levemente bidenticulados, pouco divergentes, caracteres estes que a diferenciam de $H$. indicum, que apresenta ovário 4-locular, com 1 óvulo por lóculo e fruto constituído de 4 núculas, com ápices divergentes. Nas demais características, essas duas espécies são semelhantes, sendo freqüientemente confundidas em material de herbário.

Johnston (1928) reconheceu para a espécie duas variedades: Heliotropium elongatum var. genuina e H. elongatum var. burchellii, baseando-se no tamanho da corola, as quais foram desconsideradas neste trabalho, por este caráter ser variável nos espécimes analisados. Esse mesmo autor considerou como autoridade de $H$. elongatum Hoffm. ex Roem. \& Schult. Na realidade, Roemer \& Schultes (1819) trataram a espécie como Tiaridium elongatum e apenas citaram o binômio Heliotropium elongatum, manuscrito por Hoffmansegg no exemplar Herb. Willd. n. 115, como sinônimo de T. elongatum. A publicação efetiva da combinação nova só foi feita posteriormente por Johnston (1928). Portanto, o nome correto para designar a autoridade da espécie deve ser H. elongatum (Lehm.) I.M. Johnst.

Nomes populares: tromba-de-elefante $(\mathrm{RJ})$; crista-de-galo (CE, MT, SE).

Material examinado selecionado: Brasil. Pernambuco: Afogados da Ingazeira, 11.VII.2000, J.I.M. Melo 351, fl., fr. (PEUFR); Angelim, 15.VIII.2000, J.I.M. Melo 396, fl., fr. (PEUFR); Brejão, 17.II.2000, J.I.M. Melo 234, fl., fr. (PEUFR); Caruaru, 17.XII.1999, J.I.M. Melo 202, fl., fr. (PEUFR); Cachoeirinha, 14.VIII.2000, J.I.M. Melo 380, fl., fr. (PEUFR); Canhotinho, 15.VIII.2000, J.I.M. Melo 394, fl., fr. (PEUFR); Garanhuns, 16.II.2000, J.I.M. Melo 228, fl., fr. (PEUFR); Goiana, 20.X.1999, J.I.M. Melo 190, fl., fr. (PEUFR); Ibimirim, 30.VI.2000, J.I.M. Melo 340, fl., fr. (PEUFR); Igarassu, 20.X.1999, J.I.M. Melo 184, fl., fr. (PEUFR); Iguaraci, 13.VII.2000, J.I.M. Melo 369, fl., fr. (PEUFR); Ilha de Fernando de Noronha, 05.III.1993, L.P. Félix et al. 5622, fl., fr. (PEUFR); Jaboatão, 25.XI.1997, A.L. Albuquerque s.n., fl., fr. (UFP); Lajedo, 14.VIII.2000, J.I.M. Melo 384, fl., fr. (PEUFR); Olinda, 19.IX.1997, A. Vicente et al. 6, fl., fr. (PEUFR); Ouricuri, 01.III.1971, E.P. Heringer et al. 439, fl., fr. (PEUFR); Paudalho, 20.III.2000, J.I.M. Melo 244, fl., fr. (PEUFR); Petrolina, 03.V.1984, T. Ramos et al. 5, fl., (PEUFR); Recife, 15.VIII.1958, Andrade-Lima s.n., fl. (PEUFR 1456); São João, 15.VIII.2000, J.I.M. Melo 397, fl., fr. (PEUFR); São Lourenço da Mata, 13.II.1977, I. Pontual 77-1470, fl., fr. (PEUFR); Solidão, 12.VII.2000, J.I.M. Melo 361, fl., fr. (PEUFR); Tabira, 12.VII.2000, J.I.M. Melo 352, fl., fr. 
(PEUFR); Vicência, 20.III.2000, J.I.M. Melo

248, fl., fr. (PEUFR).

Material adicional: Brasil. Bahia: Caetité, 09.III.1994, V.C. Souza et al. 5399, fl., fr. (ESA); Feira de Santana, 12.IX.1997, M.V. Moraes \& E.M. Costa-Neto 110, fl., fr. (HUEFS); Rodelas, 22.I.1987, G.O.M. Silva \& L.B. Silva 35, fl., fr. (HUEFS); Serra da Copioba, 23.II.1951, G. Pinto 589, fl., fr. (IAC). Ceará: Orós, 09.VII.1984, F.C.F. Silva 173, fl., fr. (RB); Serra de Baturité, 04.XI.1937, J. Eugenio 78, fl., fr. (RB). Maranhão: Santa Inês, 14.XII.1978, N.A. Rosa \& H. Vilar 2980, fl., fr. (RB). Mato Grosso: Campo satélite, 04.X.1976, A. Allem 104, fl. (CEN); São Félix do Araguaia, 18.III.1997, V.C. Souza et al. 14450, fl. (ESA). Mato Grosso do Sul: Aquidauana, 04.IV.1990, A.G. Silva \& S.V. Leone 12, fl., fr. (PEUFR). Minas Gerais: Pirapora, 02.X.1978, M.P. Coens 78-1053, fl. (VIC); Pouso Alegre, 27.IV.1927, F.C. Hoehne s.n., fl., fr. (SP 19208). Paraíba: Brejo da Cruz, 02.VI.1984, J.E.R. Collares \& L. Dutra 160, fl., fr. (CH); Riachão do Bacamarte, 28.VIII.1998, M.I.B. Loiola et al. 464, fl., fr. (PEUFR); Piauí: Picos, 29.VII.1964, A. Castellanos 25299, fl. (GUA). Rio de Janeiro: Paraíba do Sul, 25.VII.1984, J.P.P. Carauta et al., fl., fr. (GUA). Rio Grande do Norte: Santana, 05.XI.1968, N. Lima 36, fl. (UB). Rio Grande do Sul: Alegrete, 11.II.1990, D.B. Falkenberg \& M.E.G. Sobral 5241, fl., fr. (PEL); Cachoeira do Sul, 11.IV.1995, J.A. Jarenkow \& M. Sobral 2570, fl., fr., (PEL); Ilha da Pólvora, 11.II.1976, Z. Rosa s.n., fl., fr. (HAS 3504). São Paulo: Charqueada, 01.II.1994, K.D. Barreto et al. 1936, fl., fr. (PEL); Porto Feliz, 30.XI.1978,M.A. Cardelli \& E.A. Oliveira s.n., fr. (IAC 24948). Sergipe: Aracaju, 17.XI.1986, G. Viana \& M.L.C. Leite 2, fl., fr. (ASE).

4. Heliotropium indicum L., Sp. Pl. 1: 130. 1753.

Figs. 24-30.

Erva ou subarbusto, 0,10-1,0m alt., ereto ou decumbente. Ramos angulosos, fistulosos. Folhas alternas e subopostas no mesmo indivíduo, pecioladas; pecíolo 1,2-6,2 cm compr., parcialmente alado; lâmina 3,4-12,2 x 1,7-9 cm, membranácea, oval-elíptica a oval-deltóide, ou mais raramente rômbica, base truncada às vezes assimétrica estreitando-se para o pecíolo, ápice acuminado, margem erosa a plana, face adaxial plana, pubescente com tricomas curtos entremeados por tricomas aciculiformes, face abaxial pubescente, mais denso sobre as nervuras; venação eucamptódroma. Inflorescência 4-28 cm compr., axilar e terminal, não bracteada, congesta no ápice, pedunculada; pedúnculo 1,5-4 $\mathrm{cm}$ compr. Flores 3-5 mm compr., sésseis. Cálice 2,6-3,2 mm compr., profundamente lobado, maior que a metade do comprimento da corola, persistente no eixo da inflorescência; lobos 2,2-2,6 x 0,2$0,4 \mathrm{~mm}$, estreitamente-lanceolados, de tamanhos levemente diferentes, margem com tricomas aciculiformes esparsos. Corola 3,5-4,5 $\mathrm{mm}$ compr., hipocrateriforme, branca a arroxeada; tubo 2,5-4 mm compr., subcilíndrico, estreitando-se na fauce; lobos 0,5-0,9 $\mathrm{mm}$ compr. Estames sésseis, inseridos 0,8-1,5 mm acima da base do tubo da corola; anteras 0,8$1 \mathrm{~mm}$ compr., oblongo-ovais, ápice discretamente apiculado, livres entre si, base levemente cordada. Ovário ca. 0,5 mm compr., longitudinalmente 4-sulcado, falsamente 4locular, glabro; estilete evidente, 0,2-0,4 mm compr.; estigma 0,6 mm compr., subcapitado; óvulo 1 por lóculo, curvo, achatado. Fruto 2-3 mm diâm., mitriforme; núculas 4, agrupadas 2 a 2, com 2-3 nervuras salientes na face dorsal, divergentes, ápices acentuadamente bidentados. Semente 1 por núcula, até $1,5 \mathrm{~mm}$ compr., elipsóides, esbranquiçadas, lisas.

Distribuição geográfica: Esta é uma das espécies mais amplamente distribuídas do gênero, ocorrendo nas Américas, do México até a Argentina, incluindo Antilhas, na África Tropical, Ásia e Austrália (Fröhlich in Nash \& Moreno [1981]). No Brasil, é encontrada nas regiões Norte (AC, AM e PA), Nordeste (AL, BA, CE, MA e PE), Centro-Oeste (GO, MS e MT), Sudeste (ES, MG, RJ e SP) e Sul (PR). Em Pernambuco, H. indicum é registrada apenas para as zonas do Litoral e da Mata e 
para as ilhas do arquipélago de Fernando de Noronha, habitando preferencialmente áreas abertas, em geral próximas a cursos d'água e margens de estradas e algumas vezes em culturas.

Comentários: Heliotropium indicum foi descrita por Linnaeus (1753), com base em material procedente da Índia. É uma espécie bem definida, para a qual Johnston (1928) reconheceu sete sinônimos. Apesar de próxima de $H$. elongatum, pode ser facilmente identificada pela lâmina foliar com a face adaxial plana e pelo ovário 4-locular, com 1 óvulo por lóculo e principalmente pelo fruto constituído por 4 núculas.

Nomes populares: borragem-brava e cravode-urubu (MG); crista-de-galo (BA); fedegoso (MG, PE).

Material examinado selecionado: Brasil. Pernambuco: Amaraji, 22.VI.1999, J.I.M. Melo 197, fr. (PEUFR); Bonito, 08.I.2000, J.I.M. Melo 197, fl., fr. (PEUFR); Cabo, 17.IX.1999, J.I.M. Melo 154, fl., fr. (PEUFR); Ilha de Fernando de Noronha, 17.XII.1999, A.M. Miranda 3640, fl., fr. (HST); Maraial, 22.VII.1965, G. Teixeira 2776, fl., fr. (PEUFR); Recife, s.d., M. Ataíde 118, fr. M. (IPA); Rio Formoso, 01.III.2000, M. Oliveira 586, fl., fr. (PEUFR); São José da Coroa Grande, s.d., J.I.A. Falcão et al 830, fl., fr. (RB); Vitória de Santo Antão, 04.X.1997, A.P.S. Gomes \& A.Laurênio 476, fl., fr. (PEUFR).

Material adicional: Brasil. Acre: Tarauacá, 18.IX.1968, G.T. Prance et al. 7348, fl., fr. (R, NY); Alagoas: União dos Palmares, 05.I.1964, I.B. Pontual 55-1964, fl., fr. (PEUFR); Bahia: Anguera, 28.I.1997, E. Melo et al. 2012, fl., fr. (HUEFS, PEUFR); Andaraí, 19.X.1997, M. Alves et al. 1143, fl., fr. (PEUFR); Salvador, 07.V.1995, M.L. Guedes et al s.n., fl., fr. (ALCB 27884); Ceará: Cedro, 15.VI.1912, Loefgren 1128, fl., fr. (R); Espírito Santo: Linhares, 08.XII.1998,D.A. Folli 3313, fl. (CVRD, PEUFR); Goiás: Niquelândia, 24.X.1995, B.M.T. Walter \& S.C.S. Xavier 2848, fl., fr. (CEN); Maranhão: Açu, 11.XI.1984, M.C. Viana 176-A, fl., fr. (GUA);
Grajaú, 09.VII.1976, D. Thomaz 8, fl., fr. (PEUFR); Mato Grosso: Cáceres, 04.XI.1978, A. Allem et al. 2375, fl., fr. (CEN); Mato Grosso do Sul: Aquidauana, 04.II.1991, A. Pott et al. 2, fl., fr. (CPAP); Minas Gerais: Viçosa, UFV, 29.X.1996, G.E. Valente 237, fl., fr. (VIC); Pará: Bragança, 06.II.1961, W.A. Egler 1514, fl., fr. (IAN); Monte Alegre, 04.V.1953, Andrade-Lima 53-1296, fl., fr. (IPA); Paraná: Vila Alta, XII.1995, S.R. Ziller 1149, fl., fr. (CNPF); Rio de Janeiro: Rio de Janeiro, 30.VI.1992, M.C. Viana \& H.F. Martins 2163, fl., fr. (GUA); São Paulo: Itapira, 11.I.1994, K.D. Barreto et al. 1767, fl., fr. (ESA, SJRP).

El Salvador. Department of Sonsonate: Rio Acachapa, near headquarters of Hacienda Las Tablas, 08.V.1942, J.M. Tucker 1359, fl., fr. (IAC).

5. Heliotropium polyphyllum Lehm., Neue Schrift. Naturf. Ges. Halle 3(2): 9. 1817.

Figs. 31-40

Erva, prostrada a decumbente. Indumento seríceo, branco, revestindo ramos, folhas, inflorescências, flores e frutos. Ramos cilíndricos, com ritidoma desprendendo-se em faixas longitudinais. Folhas alternas, curtopecioladas; pecíolo 0,3-1 mm, achatado, seríceo; lâmina 0,6-1,3 x 0,1-0,2 cm, oblanceolada, cartácea a subcoriácea, base cuneada, ápice agudo, margem plana, esparsa a densamente serícea em ambas as faces; venação reticulódroma. Inflorescência 1-15,5 cm compr., terminal, solitária ou aos pares, bracteada; brácteas 3-4 x 1-1,3 mm, ovais, cartáceas, com venação semelhante às folhas, face adaxial glabra, face adaxial serícea. Flores 6-6,5 mm compr., curto-pediceladas; pedicelos ca. $0,5 \mathrm{~mm}$ compr. Cálice profundamente lobado, 3-4 mm compr., ligeiramente menor que o tubo da corola; lobos desiguais, os menores 2-2,5 x 0,60,8 mm, os maiores 3-4 x 0,8-1 mm, foliáceos, ovais a largo-ovais, margem inteira, ciliada, ápice agudo, externamente seríceos, internamente glabros. Corola 6-6,5 mm compr., hipocrateriforme, amarela, serícea 
externamente; tubo 3,6-4 $\mathrm{mm}$ compr., internamente seríceo na fauce; lobos 2,5-3 mm compr., oval-deltóides. Estames subsésseis, inseridos a $1 \mathrm{~mm}$ da base do tubo da corola; anteras ca. $1 \mathrm{~mm}$ compr., ovais, base truncada, ápice coerente, longo-caudado e pubescente. Ovário ca. 0,5 mm compr., subgloboso, 4sulcado, falsamente 4-locular, glabro; estilete cilíndrico, ca. $0,3 \mathrm{~mm}$ compr.; estigma $0,4 \mathrm{~mm}$ compr., cônico com ápice 4-denticulado; óvulo 1 por lóculo. Fruto ca. 1,5 mm diâm., subgloboso; núculas 4 , trígonas, fase dorsal serícea. Semente 1 por núcula, ca. $1 \mathrm{~mm}$ compr., trígonas, castanhas, lisas.

Distribuição geográfica: Heliotropium polyphyllum apresenta distribuição nas Américas do Norte, Central e do Sul e Antilhas, de acordo com Johnston (1928). No Brasil, está distribuída ao longo da costa atlântica; indo desde o Estado do Pará até o Rio de Janeiro, em vegetação litorânea. Foi verificado, no entanto, que no Nordeste a espécie é encontrada tanto no litoral, como em áreas de vegetação de caatinga nos estados de Pernambuco, Bahia e Rio Grande do Norte. Na região litorânea, habita dunas e ambientes de restinga, em solos arenosos, sendo uma espécie comum da vegetação de restinga. No estado de Pernambuco, este táxon encontrase distribuído nas zonas do Litoral e das Caatingas, na subzona do sertão; tanto em restinga como em áreas de caatinga, em solo arenoso.

Comentários: A espécie é muito próxima de Heliotropium ternatum, por ambas compartilharem partes vegetativas e florais revestidas por indumento seríceo e, especialmente, inflorescência bracteada e anteras coerentes pelo ápice. No entanto, $H$. polyphyllum pode ser facilmente reconhecida pela lâmina foliar de margem plana, flores amarelas e brácteas ovais. O exemplar Blanchet 2651 é um isótipo de Heliotropium polyphyllum Lehm. var. Blanchetii A. DC. proveniente da serra de Jacobina, na Bahia, o qual encontra-se depositado no herbário SP.

Nome popular: sete-sangrias (AL).
Material examinado selecionado: Brasil. Pernambuco: Cabo, 22.III.1978, AndradeLima 78-9090, fl., fr. (IPA); Itamaracá, 08.III.1986, F. Gallindo 179, fl. (IPA); Olinda, 22.VI.1961, S. Tavares 613, fl., fr. (HST); Petrolina, 26.VII.1984, G.C.P. Pinto 84-158, fl. (HRB); Santa Maria da Boa Vista, 14.IV.1988, R. Pereira 309, fl., fr. (IPA); Solidão, Serra da Santa, 28.IX.1973, G. Cavalcanti et al. 67, fl. (PEUFR).

Material adicional: Brasil: Alagoas: Maceió, 01.III.1993, M. Correia s.n., fl., fr. (MAC 0039); Marechal Deodoro, 16.V.1988, G.L. Esteves 2045, fl. (MAC). Bahia: Jacobina, Serra Jacobina, 1837, Blanchet 2651, fl., fr. (SP); Juazeiro, 26.II.1968, I. Pontual 68-762, fl. (PEUFR); Nova Remanso, 12.VIII.1984, R.P. Orlandi et al. 674, fl. (GUA); Salvador, 13.IX.1976, Equipe de Ecologia, s.n., fl., fr. (ALCB 15681). Ceará: Aquiraz, 19.X.1935, F. Drouet 2629, fl., fr. (R); Aracati, 31.I.1968, Andrade-Lima 68-5215, fl. (IPA). Maranhão: Alcântara, 28.I.1993,D. Araújo 9729, fl. (GUA); Ilha de São Luiz, 06.IV.1945, R.L. Fróes 21594, fl. (IAC). Pará: Maracanã, 30.I.1988, D. Araújo 8466, fl. (GUA); Salinópolis, 08.XII.1997, D. Araújo 10615, fl. (GUA). Paraíba: Ilha Bela, 02.XII.1997, M.B. Costa \& Silva et al. 1440, fl. (PEUFR). Piauí: Parnaíba, 15.VII.1954, Andrade-Lima 54-1976, fl. (IPA). Rio de Janeiro: Arraial do Cabo, 24.VIII.1987, D. Araújo 7957, fl., fr. (GUA); Cabo Frio, 09.V.1986, D. Araújo 7431, fl., fr. (GUA); Campos, III.1939, A. Sampaio 8170, fl., fr. (R). Rio Grande do Norte: Mossoró, 31.VIII.1984,M. Ataíde et al. 38, fl. (PEUFR); Parnamirim, 21.VII.1980, L. Coradin et al. 3204, fl., fr. (CEN). Sergipe: Pirambu, I.1974, M. Fonseca s.n., fl., fr. (ASE 00005).

6. Heliotropium procumbens Mill., Gard. Dict. 8: 10. 1768.

Figs. 41-48.

Erva ou subarbusto, $5-40 \mathrm{~cm}$ alt., ereto ou prostrado. Indumento seríceo, com tricomas de base discóide, branco, revestindo ramos, folhas e flores, conferindo aspecto verde- 


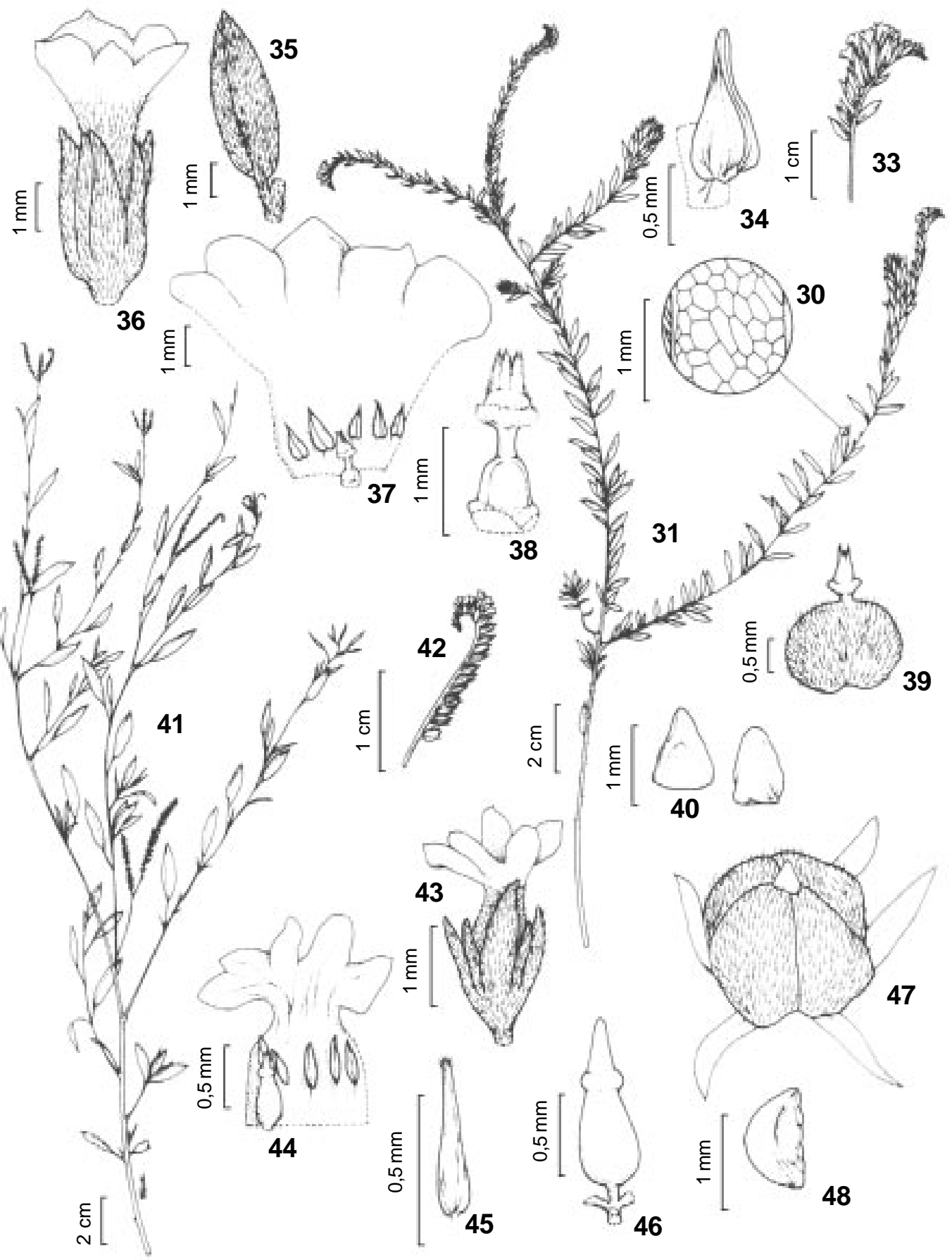

Figuras 31-48. Heliotropium polyphyllum Lehm. (L. Gomes 1): 31-40. 31.Aspecto geral do ramo; 32. Detalhe da venação da folha; 33. Detalhe da inflorescência; 34. Estame; 35. Bráctea; 36. Flor; 37. Corola aberta; 38. Gineceu; 39 . Fruto; 40. Semente, vista dorsal (L. Gomes 1). H. procumbens Mill. (Melo 186): 41-48. 41. Aspecto geral do ramo; 42. Detalhe da inflorescência; 43. Flor; 44. Corola aberta; 45. Estame; 46. Gineceu; 47. Fruto; 48. Semente, face lateral. 
cinéreo a planta. Ramos cilíndricos, verdecinéreos. Folhas alternas, pecioladas; pecíolo 0,4-1,5 cm compr., sub-cilíndrico, sulcado na face ventral; lâmina 1-3,8 x 0,3-1,3 cm, subcarnosa, estreito-elíptica a elíptica, oblongoelíptica, base atenuada, ápice agudo e mucronado, margem inteira, faces adaxial e abaxial esparso a denso seríceas; venação eucamptódroma, face adaxial com nervuras secundárias pouco evidentes, face abaxial com nervura principal proeminente. Inflorescência 1-9 cm compr., axilar e terminal, inteira ou bifurcada, 1-4 partindo de um mesmo ponto, seríceas, pedunculadas, não bracteada; pedúnculo 0,9-3 cm compr. Flores 1,6-2 mm compr., curto-pediceladas; pedicelo $0,6-0,9 \mathrm{~mm}$ compr. Cálice profundamente lobado, ligeiramente menor que o tubo da corola, persistente no eixo da inflorescência; lobos 11,3 mm compr., oval-lanceolados. Corola 1,5-2 mm compr., tubular-hipocrateriforme, branca, fauce amarela; tubo 1-1,4 mm compr., cilíndrico; lobos ca. 0,3 mm compr., obovais, suberetos. Estames subsésseis, inseridos $1 / 3$ da base do tubo da corola; anteras $0,5-0,7$ m compr., ovallanceoladas, ápice caudado, livre. Ovário ca. 0,3 mm compr., subgloboso, 4-locular, seríceo; estilete inconspícuo, recoberto pelo estigma; estigma $0,3 \mathrm{~mm}$ compr., cônico com disco estigmático $0,4 \mathrm{~mm}$, pubescente; óvulo 1 por lóculo. Fruto ca. $1 \mathrm{~mm}$ diâm., subgloboso; núculas 4 , trígonas, hirsutas. Semente 1 por núcula, 1 mm compr., trígonas, esbranquiçadas, lisas.

Distribuição geográfica: Heliotropium procumbens apresenta distribuição americana, ocorrendo desde o sul dos Estados Unidos até a Argentina, incluindo Antilhas (Fröhlich in Nash \& Moreno [1981]). Para o Brasil, o táxon apresenta-se amplamente distribuído, ocorrendo nas regiões Norte (AM), Nordeste (BA, CE, PB e PB), Centro-Oeste (GO, MS e MT), Sudeste (MG) e Sul (RS). No estado de Pernambuco, $H$. procumbens foi a espécie coletada com maior freqüência durante a realização desse estudo. Geralmente é encontrada simpatricamente com $H$. angiospermum e H. elongatum, formando grandes populações. Ocupa os mais variados ambientes, habitando preferencialmente locais úmidos; como leitos de rios e riachos, margens de açudes e barragens, além de áreas sujeitas a inundações temporárias, em solos arenosos, argilosos e pissarentos.

Comentários: Heliotropium procumbens é facilmente reconhecida pela coloração verdecinéreo dos ramos e folhas, que reveste também flores e frutos e pelas anteras com ápice caudado. Os indivíduos apresentam-se geralmente prostrados, bastante difusos, ou eretos.

Nomes populares: crista-de-galo, erva-dexangô e malvinha(BA); mato-azul, erva-azul e erva-çazu (PE).

Material examinado selecionado: Brasil. Pernambuco: Afogados da Ingazeira, 11.VII.2000, J.I.M. Melo 349, fl., fr. (PEUFR); Arcoverde, 29.VI.2000, J.I.M. Melo 335, fl. (PEUFR); Belém de São Francisco, 19.VII.1967,E. Tenório 67-317, fl., fr. (IPA); Brejão, 17.II.2000, J.I.M. Melo 236, fl., fr. (PEUFR); Brejinho, 09.VI.2000, J.I.M. Melo 317, fl., fr. (PEUFR); Cachoeirinha, 14.VIII.2000, J.I.M. Melo 379, fl., fr. (PEUFR); Calçado, 14.VIII.2000, J.I.M. Melo 386, fl., fr. (PEUFR); Caruaru, 18.XII.1999, J.I.M. Melo 214, fl. (PEUFR); Exu, 09.XI.1986, V.C. Lima 427, fl., fr. (IPA); Ferreiros, 04.X.1958, AndradeLima 58-5768, fl., fr. (IPA); Garanhuns, 16.II.2000, J.I.M. Melo 223, fl. (PEUFR); Goiana, 20.X.1999, J.I.M. Melo 186, fl., fr. (PEUFR); Iguaraci, 13.VII.2000, J.I.M. Melo 370, fl., fr. (PEUFR); Itacuruba, 26.II.1988, R.P. Orlandi 855, fl., fr. (HUEFS); Parnamirim, 01.IX.1958, Andrade-Lima 58-3248, fl., fr. (PEUFR); Pesqueira, 29.VI.2000, J.I.M. Melo 331, fl., fr. (PEUFR); Petrolina, 23.VI.1983, $L$. Coradin et al. 5966, fl., fr. (CEN); Quixaba, 13.VII.2000, J.I.M. Melo 363, fl., fr. (PEUFR); Recife, 19.IX.1997, A.P.S. Gomes 465, fl., fr. (PEUFR); Serra Talhada, 16.VII.1961, D. Alencar s.n., fl., fr. (PEUFR 1098); Sertânia, 23.VII.1994, A.M. Miranda et al. 1936, fl., fr. (PEUFR); Solidão, 12.VII.2000, J.I.M. Melo 360, fl., fr. (PEUFR); Tabira, 12.VII.2000, J.I.M. 
Melo 356, fl., fr. (PEUFR); Triunfo, 25.II.1986, V.C. Lima \& F. Gallindo 37, fr. (IPA); Vertentes, 11.V.2000, J.I. M.Melo 275, fl., fr. (PEUFR).

Material adicional: Brasil. Amazonas: Abunã, 16.VII.1998, G.T. Prance et al. 6199, fl., fr. (R); Bahia: Caraíba, 07.VIII.1994,M.L. Guedes s.n., fl., fr. (ALCB 26953); Jacobina, 06.VII.1996, H.P. Bautista et al. 3460, fl., fr. (ALCB); Morro do Chapéu, 04.III.1997, R.M. Harley et al 6002, fl., fr.. (ALCB); São Sebastião do Passe, 18.X.1998, A.F.S. Nascimento et al. 91, fl., fr. (ALCB); Ceará: Serra de Baturité, 14.X.1939, J. Eugenio 80, fr. (RB); Goiás: Campinaçu, 09.X.1995, B.M.T. Walter 2782, fl., fr. (CEN); Mato Grosso: Poconé, 11.IX.1991, M. Schessl 2207, fl., fr. (CH); Mato Grosso do Sul: Corumbá, 12.VII.1992, E.F. Rocha et al. 15, fl., fr. (UFMS); Entre Rios, 17.VII.1980, L. Coradin et al. 3035, fl., fr. (CEN); Minas Gerais: Santa Luzia, 06.I.1935, M. Barreto 2133, (MHN); Viçosa, s.d., Kuhlmann s.n., fl., fr. (VIC 2562); Paraíba: Pocinhos, 08.VII.1994, L.P. Félix et al. 6544, fl., fr. (PEUFR); São João do Cariri, 23.XII.1977, I. Pontual 77-1367, fr. (PEUFR); Soledade, 13.III.1986, M. Sales et al. 43, fl., fr. (PEUFR); Rio Grande do Sul: Camaquã, 28.V.1989, J.A. Jarenkow \& J.L. Waechter 1313, fl., fr. (PEL); São Leopoldo, 12.I.1951, A. Sehnem 7816, fr. (PEL). Argentina. Corrientes: Dept. ${ }^{\circ}$ Capital, 03.XI.1971, A. Krapovickas \& C.L. Cristóbal s.n., fl., fr. (IAC 22599). Bolívia. Dept ${ }^{\circ}$. St ${ }^{\mathrm{a}}$. Cruz: Prov. Andres Ibanez, 20.I.1987, M. Nee 33666, fl., fr. (PEL).

7. Heliotropium ternatum Vahl, Symb. Bot. 3:21. 1794.

Figs. 49-58.

Subarbusto, $15-30 \mathrm{~cm}$ alt., ereto a semiprostrado. Ramos cilíndricos, acinzentados a amarronzados, tomentosos a seríceos, com tricomas esbranquiçados. Folhas alternas, sésseis a pecioladas; pecíolo 1-2 mm compr., seríceo; lâmina 0,7-3 x 0,1-0,5 cm, cartácea, estreitamente-elíptica, lanceolada a linear, base aguda, ápice agudo, margem revoluta, face adaxial esparso a densamente serícea, face abaxial tomentosa, com tricomas longos sobre a nervura principal; venação reticulódroma. Inflorescência 1,5-18 cm compr., terminal e axilar, congesta no ápice, serícea, pedunculada, bracteada; pedúnculo 1,4-2 cm compr., brácteas 2,5-2,7 x 0,3-0,4 mm, estreitamente-elípticas, margem ciliada, seríceas. Flores 3-4 mm compr., subsésseis. Cálice profundamente lobado, lobos 2-2,5 x 0,5-0,7 mm compr., exibindo tamnhos levemente diferentes, ovalelípticos a lanceolados, seríceos em ambas as faces. Corola 3-4 mm compr., tubularhipocrateriforme, alva com fauce amarela, serícea externamente; tubo 2-2,7 mm compr., constricto próxima a base e na fauce; lobos 1,3$2 \mathrm{~mm}$ compr., obovais. Estames subsésseis, inseridos na constrição a ca. $1 \mathrm{~mm}$ da base, envolvendo o estigma; anteras ca. $1 \mathrm{~mm}$ compr., ovais, base cordada, ápice longocaudado, coerente. Ovário 0,3-0,4 mm compr., globoso, falsamente 4-locular, glabro; estilete ca. $0,5 \mathrm{~mm}$; estigma estreito-cônico, 0,6-0,8 mm compr., ápice 2-partido, disco estigmático diâmetro menor que o ovário; óvulo 1 por lóculo. Fruto 1,5-1,8 mm diâm., globoso; núculas 4, trígonas, densamente hirsutas. Semente 1 por núcula, $1 \mathrm{~mm}$ compr., orbiculares, amarronzadas, lisas.

Distribuição geográfica: Heliotropium ternatum é uma espécie exclusivamente americana, sendo referida por Fröhlich apud Nash \& Moreno (1981) para o México, Guiana Inglesa, Venezuela, Brasil e Antilhas. No Brasil, a espécie apresenta-se distribuída nas regiões Nordeste (BA, PB, PE, PI, RN e SE) e Sudeste (MG). Em Pernambuco, é encontrada na zona das Caatingas; exclusivamente no domínio do semi-árido, em vegetação de caatinga hipo e hiperxerófila, especialmente no período das chuvas.

Comentários: De acordo com Förther (1998), a espécie foi descrita com base em material proveniente da Jamaica, o qual encontra-se incorporado no Gray Herbarium. É facilmente reconhecida pelas folhas estreito-elípticas, lanceoladas a lineares, com face adaxial serícea, abaxial tomentosa e margem revoluta e 

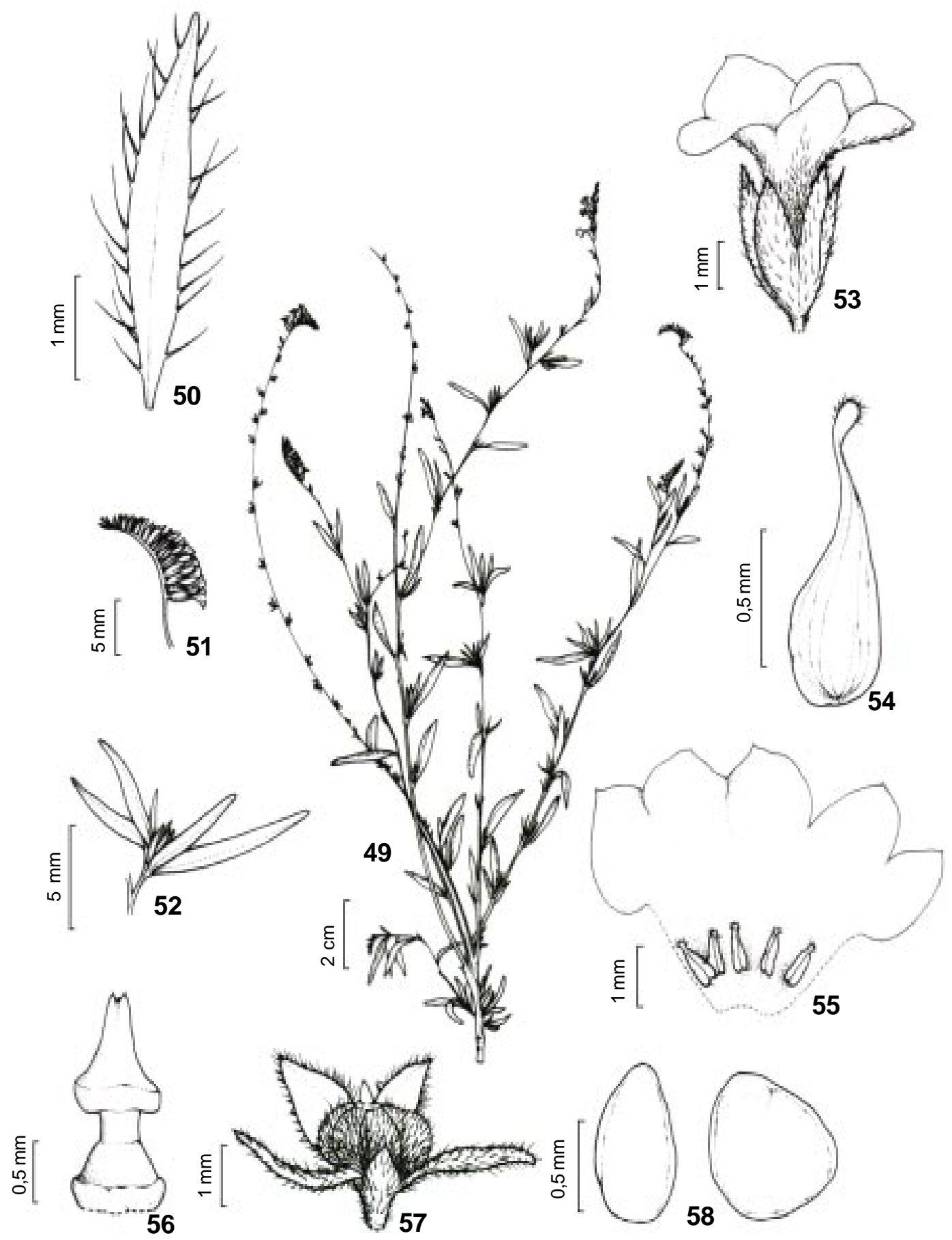

Figuras 49-58. Heliotropium ternatum Vahl (Heringer 635): 49. Aspecto geral do ramo; 50. Detalhe da bráctea; 51. Detalhe da inflorescência; 52. Detalhe do ramo, mostrando as folhas; 53. Flor; 54. Estame; 55. Corola aberta; 56. Gineceu; 57. Fruto; com cálice persistente; 58. Semente, vista frontal. 


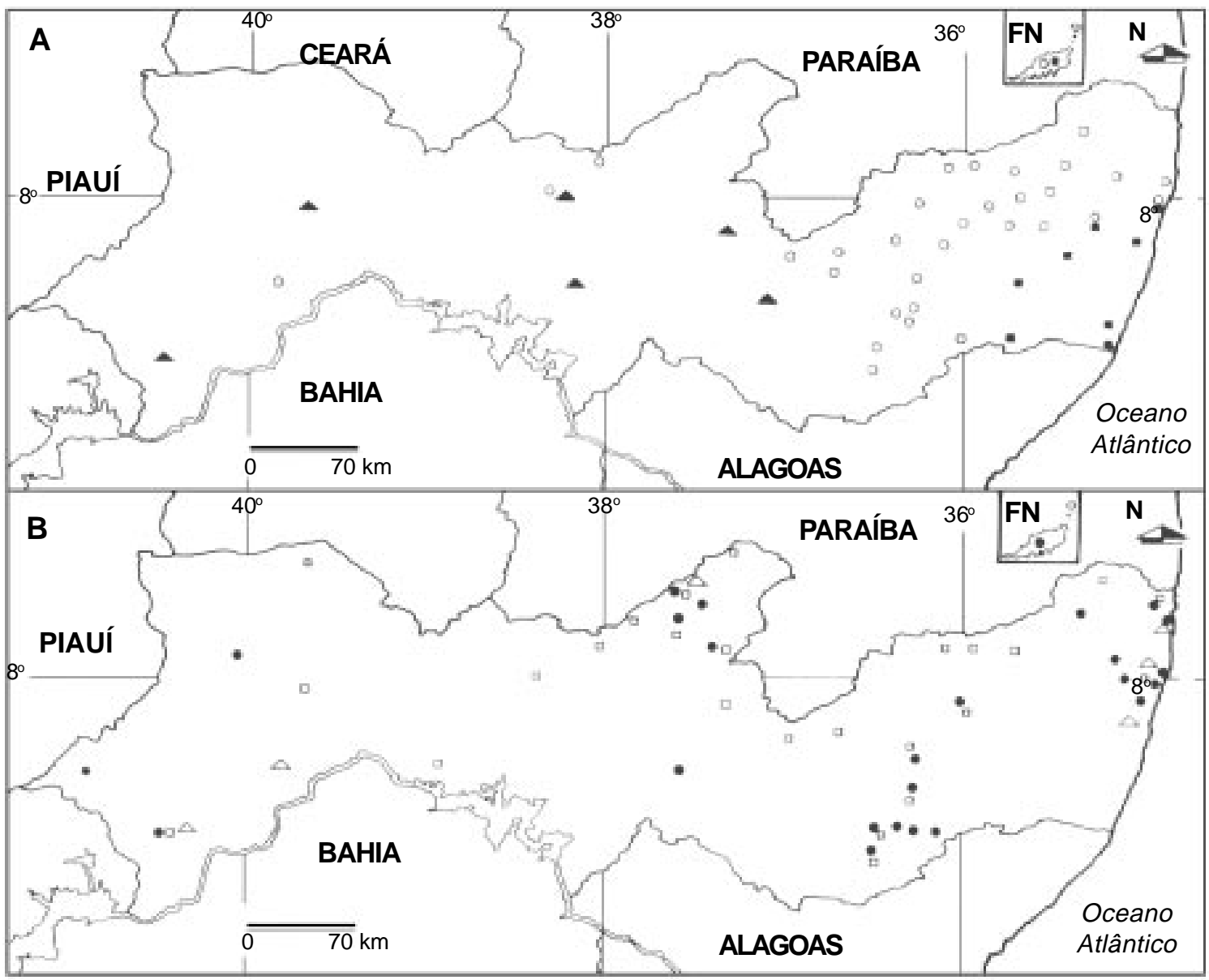

Figura 59. Distribuição geográfica do gênero Heliotropium ocorrente em Pernambuco, nordeste do Brasil: A. H.

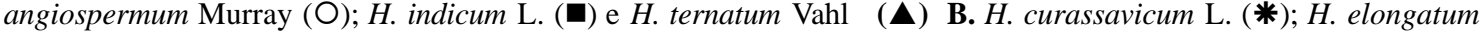

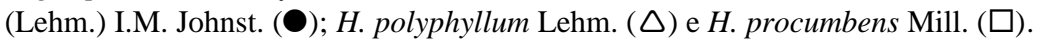

especialmente pelas anteras coerentes pelo ápice. Johnston (1935) estudando as espécies de Heliotropium das Guianas e Venezuela propõe uma variedade: H. ternatum var. fumana, para acomodar espécimes com folhas lineares e indumento estrigoso.

Material examinado selecionado: Brasil. Pernambuco: Buíque, 19.VI.1994, A.M. Miranda et al. 1827, fl. (PEUFR); Floresta, 13.VI.1995, E. Ferraz 04, fl., fr. (IPA); Parnamirim, 23.V.1984, F. Araújo 90, fl. (PEUFR); Petrolina, 07.IV.1979, L. Coradin et al. 1399, fl. (CEN); Serra Talhada, 08.V.1971, E.P. Heringer et al. 635, fl., fr. (PEUFR); Sertânia, 24.VI.1998, R.G. Oliveira et al. 87, fl., fr. (PEUFR).
Material adicional: Brasil. Bahia: Abaíra, 23.X.1999, E.M. Silva 289, fl., fr. (HUEFS); Juazeiro, 28.IV.1973, A. Valeriano s.n., fl., fr. (ALCB 3502); Juçara, 02.IV.1984, H.P. Bautista et al. 916, fl., fr. (HRB, ALCB, GUA, MT, HUEFS). Minas Gerais: Belo Horizonte, 15.XII.1932, Mello-Barreto 2139, fl., fr. (MHN); Rio Verde, 19.I.1945, C. Shimoya s.n., fl. (VIC 3576). Paraíba: Patos, 22.VI.1935, D. Bento Pickel 3896, fr. (IPA). Piauí: São Raimundo Nonato, Serra da Capivara, s.d., $L$. Emperaire 608-1979, fl., fr. (IPA 28988). Rio Grande do Norte: Mossoró, s.d., S. Tavares 693, fl., fr. (HST). Sergipe: Poço Verde, 06.V.1982, G. Viana 437, fl., fr. (ASE). 


\section{CONCLUSÕES}

Foram verificadas sete espécies acomodadas em quatro seções: 1) Heliotropium sect. Schobera ( $H$. angiospermum Murray); 2) Heliotropium sect. Platygyne (H. curassavicum L.); 3) Heliotropium sect. Tiaridium (H. elongatum [Lehm.]I.M.Johnst. e $H$. indicum L.) e 4) Heliotropium sect. Orthostachys (H. polyphyllum Lehm., H. procumbens Mill. e H. ternatum Vahl.);

As características mais importantes para o reconhecimento das espécies de Heliotropium ocorrentes em Pernambuco são: a presença ou ausência de brácteas na inflorescência, o ápice das anteras se coerentes ou não entre si, a forma do estigma e o número de núculas do fruto.

As espécies mais amplamente distribuidas são $H$. angiospermum, $H$. elongatum e $H$. procumbens; sendo $H$. procumbens, a espécie mais frequente na Zona das Caatingas. $H$. polyphyllum ocorre em vegetação litorânea, em áreas de restinga, penetrando para oeste no domínio do semi-árido enquanto $H$. indicum apresenta distribuição nas Zonas do Litoral e da Mata. Heliotropium ternatum e $H$. curassavicum ocorrem exclusivamente na Zona das Caatingas, sendo que esta última ocorre somente em habitats salinos.

Considerando-se o amplo espectro de distribuição geográfica associada aos diferentes ambientes, onde a maioria das espécies estudadas apresenta distribuição exclusivamente americana (Heliotropium curassavicum L. e $H$. indicum L. são cosmopolitas), verifica-se uma acentuada uniformidade morfológica para as mesmas.

\section{AGRADECIMENTOS}

$\mathrm{O}$ primeiro autor agradece ao $\mathrm{CNPq}$, Conselho Nacional de Desenvolvimento Científico e Tecnológico, pela concessão de bolsa de formação de pesquisador - nível II (Proc. n. ${ }^{\circ}$ 130571-1999/7). Agradecemos ao Programa de Pós-Graduação em Botânica da
Universidade Federal Rural de Pernambuco, pelas facilidades concedidas, e aos curadores dos diferentes herbários pelo empréstimo, doação e permissão para consulta das coleções.

\section{REFERÊNCIAS BIBLIOGRÁFICAS}

Akhani, H. \& Förther, H. 1994. The genus Heliotropium L. (Boraginaceae) in Flora Iranica Area. Sendtnera 2: 187-276.

Al-Nowaihi, A. S., Khalifa, S. F. \& Hamed, K. 1987. A contribution to the taxonomy of Boraginaceae. Phytologia 62(2): 107125.

Andrade-Lima, D. de. 1960. Estudos fitogeográficos de Pernambuco. Arquivos do Instituto de Pesquisa Agronômica de Pernambuco, Recife, v. 5.

Barroso, G. M., Andreata, R. H. P. \& Lima, M. P. M. 1994. Morfologia e inflorescências. Rio de Janeiro. Universidade Santa Úrsula, Instituto de Ciências Biológicas e Ambientais, 117p. il. (mimeogr.)

Barroso, G. M., Morim, M. P., Peixoto, A. L., Ichaso, C. L. F. 1999. Frutos e sementes: morfologia aplicada à sistemática de dicotiledôneas. Viçosa. Universidade Federal de Viçosa (Imprensa Universitária), 443p.

Bentham, G. \& Höoker, J. H. 1873/1876. Boraginaceae. In: G. Bentham \& J. D.Hooker. Genera Plantarum. London, Lovell Reeve \& Co., London. v. 2, p. 832-869.

Bridson, D. \& Forman, L. 1998. The herbarium handbook. Royal Botanic Gardens: 3.ed.

De Candolle, A. P. 1845. Boraginaceae. In: Prodromus systematis naturalis regni vegetabilis. Paris, v.9, p.466-559.

Förther, H. 1998. Die infragenerische Gliederung der Gattung Heliotropium L. und ihre Sterllung innerhalb der subfam. Heliotropioideae (Schrad.) Arn. (Boraginaceae). Sendtnera 5: 35-241. 
Fresenius, G. 1857/1863. Heliotropium. In: Martius, C.F.P. von; Eichler, A.W. \& Urban, I. Flora Brasiliensis. München, Wien, Leipzig, v.8, part 1, p.32-48.

Fröhlich, M. W. in Nash, D. L. \& Moreno, N. P. 1981. Heliotropium. In: Gómez Pompa, A. \& Moreno, N.P. Flora de Veracruz. Xalapa, Instituto Nacional de Investigaciones sobre recursos Bióticos, v. 18.

Gangui, N. 1955. Las especies silvestres de Heliotropium de la República Argentina. Revista de la Facultad de Ciencias Exactas, Físicas y Naturales 2: 481560.

Gentry, A. H. 1993. A Field Guide to the families and genera of woody plants of the Northwest South America. Washington, DC.

Gentry, J. L. \& Janos, D. 1974. A preliminar generic key and geographic check-list of the Boraginaceae family in Central America and Panama.Phytologia 27 (6): 445-455.

Gibson, D. 1970. Boraginaceae. In: Standley, P. C. \& Steyermark, J. A. Flora of Guatemala. Fieldiana: Botany 24: 111167.

Gomes, A. P. S. 1999. Florística e fitossociologia da vegetação arbustiva subcaducifólia no município de Buíque, Pernambuco. Recife, Universidade Federal Rural de Pernambuco. Dissertação de Mestrado. Departamento de Biologia.

Guimarães, E. F., Barroso, G. M., Ichaso, C. L. F. \& Bastos, A. R. 1971. Boraginaceae. In: Flora da Guanabara. Rodriguésia 38: 194-220.

Gürke, M. 1897. Heliotropioideae. In:Engler, H. G. A. \& Prantl, K. A. E. Die natürlichen Pflanzenfamilien. 3. Aufl. Leipzig (Wilhelm Engelmann). v. 4, p. 71131, fig. 37-39.
Harvey, Y. B. 1995. Boraginaceae. In: Stannard, B. L. Flora of the Pico das Almas, Chapada Diamantina - Bahia, Brasil. Kew (Royal Botanic Gardens).

Holmgren, P. K., Holmgren, N. H. \& Barnett, L. C. (eds.) 1990. Index Herbariorum. Part 1: The Herbaria of the world. Ed. 8. New York (New York Botanical Garden).

Hickey, L. J. 1973. Classification of the architecture of dicotyledonous leaves. American Journal of Botany 60:17-33.

Johnston, I. M. 1928. Studies in Boraginaceae VII: The South American species of Heliotropium. Contributions from the Gray Herbarium of Harvard University 81: 3-73.

1935. Studies in Boraginaceae X: The Boraginaceae of Northeastern South America. Journal of the Arnold Arboretum 16 (1): 1-64.

Lawrence, G. H. M. 1951. Taxonomia das plantas vasculares. v.2. Lisboa. Fundação Calouste Gulbenkian, 854p.

Lehmann, J. G. C. 1817. Neue Schriften Naturf. Ges. Halle 3 (2): 9.

Linnaeus, C. 1753. Species Plantarum. London, The Ray Society, v.1, p.130-131.

Macbride, J.F. 1960. Boraginaceae. In: Macbride, J.F. Flora of Peru. Fieldiana: Botany 13: 539-609.

Miller, P. 1768. The gardeners dictionary, ed. 8. London.

Miranda, M. M. B. de \& Andrade, T. A. P. 1990. Fundamentos de palinologia: principais tipos polínicos do litoral cearense. Fortaleza. Universidade Federal do Ceará (Imprensa Universitária).

Murray, J. A. 1770. Prodromus designationis stirpium gottingensium [Göttingen] 3: 217.

Nowicke, J. 1969. Boraginaceae. In: Woodson Jr., R. E.: Schery, R. W. \& Collaborators. Flora of Panama. Annals of the Missouri Botanical Garden 56: 33-69.

Rodriguésia 55 (84): 65-87. 2004 
Payne, W. W. 1978. A glossary of plant hair terminology. Brittonia 30: 239-255.

Radford, A. E., Dickison, W. C., Massey, J. R. \& Bell, C. R. 1974. Vascular Plant Systematics. New York. Harper \& Row, $891 \mathrm{p}$.

Roemer, J. J. \& Schultes, J. A. 1819. Systema vegetabilium. Stuttgart (Sumtibus J.G.Cottae), vol. 4, 736p.

Sales, M. F., Mayo, S. J. \& Rodal, M. J. N. 1998. Plantas vasculares das florestas serranas de Pernambuco: um checklist da flora ameaçada dos brejos de altitude de Pernambuco, Brasil. Recife. Universidade Federal Rural de Pernambuco (Imprensa Universitária), 130p.

Smith, L. B. 1970. Boragináceas. In: Reitz, P. R. Itajaí, Flora Ilustrada Catarinense.

Swingle, D. B. 1993. A textbook of Systematic Botany. $3^{\text {rd }}$ ed., New York. Oxford University Press, 355p.

Tournefort, J. P. 1719. Institutiones Rei Herbariae. Parisiis.

Vahl, M. 1794. Symbolae Botanicae 3: 21. Havniae. 